\title{
Monoclonal Antibody and Fusion Protein Biosimilars Across Therapeutic Areas: A Systematic Review of Published Evidence
}

\author{
Ira Jacobs $^{1}$ - Danielle Petersel ${ }^{1}$ Lesley G. Shane ${ }^{2}$ Chee-Keng $\mathrm{Ng}^{3}$ • \\ Carol Kirchhoff $^{4} \cdot$ Gregory Finch $^{5} \cdot$ Sadiq Lula $^{6}$
}

Published online: 2 November 2016

(c) The Author(s) 2016. This article is published with open access at Springerlink.com

\begin{abstract}
Background Despite regulatory efforts to formalize guidance policies on biosimilars, there remains a need to educate healthcare stakeholders on the acknowledged definition of biosimilarity and the data that underpin it.

Objectives The objectives of the study were to systematically collate published data for monoclonal antibodies and fusion protein biosimilars indicated for cancer, chronic inflammatory diseases, and other indications, and to explore differences in the type and weight (quantity and quality) of available evidence.
\end{abstract}

Gregory Finch was an employee of Pfizer at the time the study was conducted.

Electronic supplementary material The online version of this article (doi:10.1007/s40259-016-0199-9) contains supplementary material, which is available to authorized users.

Ira Jacobs

ira.jacobs@pfizer.com

1 Global Established Pharma Medicines Development Group, Pfizer Inc., 235 East 42nd Street, New York, NY 10017-5755, USA

2 Outcomes and Evidence, Global Health and Value, Pfizer Inc., New York, NY, USA

3 Analytical Research and Development, Biotherapeutics Pharmaceutical Sciences, Pfizer Inc., Andover, MA, USA

4 Global Technology Services, Biotechnology and Aseptic Sciences, Pfizer Inc., Chesterfield, MO, USA

5 Drug Safety Research and Development, Pfizer Inc., Groton, CT, USA

6 Envision Pharma Group, London, UK
Methods MEDLINE, Embase, and ISI Web of Science were searched to September 2015. Conference proceedings $(n=17)$ were searched 2012 to July 2015. Included studies were categorized by originator, study type, and indication. To assess data strength and validity, risk of bias assessments were undertaken.

Results Across therapeutic areas, 43 named (marketed or proposed) biosimilars were identified for adalimumab, abciximab, bevacizumab, etanercept, infliximab, omalizumab, ranibizumab, rituximab, and trastuzumab originators. Infliximab CT-P13, SB2, and etanercept SB4 biosimilars have the greatest amount of published evidence of similarity with their originators, based on results of clinical studies involving larger numbers of patients or healthy subjects ( $N=1405,743$, and 734 , respectively). Published data were also retrieved for marketed intended copies of etanercept and rituximab.

Conclusions This unbiased synthesis of the literature exposed significant differences in the extent of published evidence between molecules at preclinical, clinical, and post-marketing stages of development, providing clinicians and payers with a consolidated view of the available data and remaining gaps.

\section{Key Points}

The quantity and quality of published preclinical and clinical data for approved or proposed biosimilars and intended copies varies widely.

This synthesis of available evidence provides an unbiased resource to inform and support clinical decision making. 


\section{Introduction}

The arrival of biosimilars for a number of key recombinant biologics, including the first approved monoclonal antibodies (mAbs) [1-3], is expected to provide cost savings to healthcare systems and offers the potential to expand patient access to important medicines $[4,5]$. Outside of the EU or the USA, experience of the regulatory pathway leading to approval of $\mathrm{mAb}$ or fusion protein biosimilars by major health authorities remains limited. Nevertheless, regulatory environments across all markets are evolving rapidly, with extensive global industrial biologic development and manufacturing experience [6,7], accompanied by rising standards of clinical care. Over the past few years, there has also been a steady increase in the body of evidence-in the form of robust peer-reviewed publications available in the public domain-for biosimilars on the market and in development.

CT-P13 (Remsima $^{\mathrm{TM}} /$ Inflectra $^{\mathrm{TM}}$; Celltrion, South Korea/Hospira, USA) was the first EU-approved mAb infliximab biosimilar, obtaining market authorization in September 2013, across all approved indications of Remicade $^{\circledR}$ for rheumatoid arthritis (RA), Crohn's disease, ulcerative colitis, ankylosing spondylitis, psoriatic arthritis, and psoriasis [8, 9]. In May 2016, SB2 (Flixabi ${ }^{\circledR}$; Samsung Bioepis), an infliximab biosimilar, was also approved in the EU for the treatment of adults with RA, Crohn's disease, ulcerative colitis, ankylosing spondylitis, psoriatic arthritis, and psoriasis [10]. In January 2016, SB4 (Benepali ${ }^{\circledR}$; Biogen, Samsung Bioepis, South Korea) became the first etanercept biosimilar to Enbrel ${ }^{\circledR}$ to be approved in the EU for the treatment of adults with moderate to severe RA, psoriatic arthritis, non-radiographic axial spondyloarthritis, and plaque psoriasis [11]. Marketing authorization applications for ABP 501 (adalimumab; Amgen) and GP2015 (etanercept; Sandoz, Switzerland) were submitted to the European Medicines Agency (EMA) in 2015 [12-14] and were still undergoing evaluation at the time of writing this article.

In the USA, the FDA guidance documents on scientific and quality considerations in the demonstration of biosimilarity were finalized in April 2015 [15]. Almost 1 year later, the FDA released draft guidance for industry on the labeling of biosimilar products, which provides an overview of the FDA's recommendations for biosimilar labels and is intended to support the development of draft labeling for submission in proposed biosimilar product applications [16, 17]. In April 2016, the FDA approved the infliximab biosimilar, CT-P13 for multiple indications [18]. CT-P13 is the first mAb biosimilar to be approved in the USA and only the second biosimilar to be granted FDA approval [18, 19]. In July 2016, the FDA Arthritis Advisory Committee unanimously voted to recommend approval of Sandoz's etanercept biosimilar, GP2015 [20]. Also in July 2016, the FDA advisory panel voted in favor of recommending approval for ABP 501, Amgen's proposed biosimilar of adalimumab [21].

Biosimilars are thus required to meet rigorous regulatory standards on biosimilarity and, as such, the term 'biosimilars' is applied to products that meet these standards. In contrast, the terms 'intended copies' or 'non-comparable biologics' are applied to products that have not undergone rigorous similarity exercises but are marketed nevertheless $[1,22,23]$. The published data available on these products are insufficient to provide robust evidence compared with the originator product [24].

Despite regulatory efforts across major markets to formalize guidance policies on biosimilars, there remains an ongoing need to inform and educate healthcare professionals and payers on the acknowledged definition of biosimilarity and to keep stakeholders abreast of any developments regarding the labeling, substitution, and indication extrapolation of biosimilar candidates. Payers and clinicians would benefit from more information on the weight and breadth of evidence available for proposed or approved biosimilars to support more informed prescribing and coverage decisions.

Currently, no published reviews are available that have systematically summarized all of the available studies on biosimilars across all stages of development and across multiple therapeutic areas. With these considerations in mind, a comprehensive literature review was undertaken to identify, collate, and summarize published empirical evidence on proposed or approved $\mathrm{mAb}$ and fusion protein biosimilars indicated for cancer, chronic inflammatory diseases, and other indications. The intent of this research was to provide a robust overview of biosimilar molecules currently in development, in human clinical trials, or on the market, and to explore differences in the type and weight of evidence. The results presented in this study represent findings from the published literature (up to the analysis cut-off date for this article, 3 September 2015) and provide insight on the dataset available for these classes of biosimilars. The authors also reviewed planned, ongoing, or completed trials with currently unpublished data (up to the analysis cut-off date for this article, 21 September 2015).

This work is intended to provide an introduction to the field of biosimilars and reports on the methodology and high-level findings of the systematic literature review (SLR). A detailed analysis of the full study data and remaining knowledge gaps for each therapeutic area will be presented in a series of follow-on manuscripts currently in development and will include all reported outcomes across the identified empirical study types, quality assessment results, and a thematic analysis of the retrieved non-empirical publications. 


\section{Methods}

\subsection{Systematic Literature Review}

The MEDLINE/Medline in process and Embase electronic databases were searched using the OVIDSP interface from database inception to 3 September 2015. The ISI Web of Science database was searched up to 3 September 2015. The search strategy was executed on 27 April 2015 and was refreshed on 3 September 2015 to capture recent fulltext publications. First, search terms were used that capture 'mAb', 'fusion protein', or 'interleukin-1 receptor-antagonist' terms. Second, search terms were used that encompass the different terminologies for biosimilar products, including, for example, 'biosimilars', 'subsequent entry biologics', 'follow-on biologics', 'follow-on proteins', 'biocomparables', 'biogenerics', 'similar biotherapeutic products', and 'intended copies' or 'biobetters' (which were analyzed separately). Controlled vocabulary and freetext terms were used, and the search results were filtered using the study designs of interest. The final search result from each database was limited to references published in the English language. Included publications were required to contain both a 'mAbs/fusion protein' term and a 'biosimilars' term. To capture the latest studies not yet published as full-text articles and/or supplement results of previously published studies, a hand-search of key conference proceedings $(n=17)$ was conducted for the period of 1 January 2012 to 31 July 2015. The complete list of conference proceedings can be found in Table S1 in the Electronic Supplementary Material (ESM) and includes disease-specific (i.e., for oncology or chronic inflammatory disease), health economics and outcomes research, regulatory/payer-focused, and manufacturing/developmentthemed meetings that were prioritized on the basis of the quantity and quality of biosimilar content in 2014. Searches were also conducted using the US National Library of Medicine (NLM) ClinicalTrials.gov registry to identify biosimilars in development that did not appear in the published literature or in the identified congresses. Handscreening was used to identify relevant records due to the limited extent of the searches available for ClinicalTrials.gov.

\subsection{Eligibility Criteria}

All publication types with a 'biosimilar' and either a ' $\mathrm{mAb}$ ' and/or 'fusion protein' term were included, with the exception of case studies/case reports, short news reports, or congress overviews. The publication types of interest were empirical publications of studies (i.e., analytical, functional, or nonclinical [collectively referred to as preclinical]), clinical (i.e., pharmacokinetics $[\mathrm{PK}] /$ safety trials in healthy subjects or patients and comparative safety/efficacy trials), observational (prospective, retrospective, and post-marketing), and non-empirical publications including publications reporting manufacturing or supply topics and themes, review articles, opinion pieces or commentaries, regulatory/policy-related content and published descriptions of product-related patient support programs, and any other non-empirical publication type relevant to biosimilars meeting the inclusion criteria.

\subsection{Study Categorization}

A stepwise approach was undertaken to categorize publications by biosimilar molecule, indication, reference product, and study type (ESM Table S2). Two independent reviewers separated empirical publications disclosing 'candidate development' or brand names of biosimilars (collectively referred to as 'named biosimilars' hereafter) from non-empirical publications and from those that did not disclose the name of a biosimilar. For the empirical studies, one reviewer extracted information regarding the reference biologic (where available), the named biosimilar, indication, study type, study characteristics, study outcomes, and parameters assessed. A blinded second reviewer classified a $10 \%$ sample of these; in the event of finding a 5\% discrepancy, the database was re-evaluated. Any discrepancies were resolved by consensus among reviewers. A similar approach was taken for categorization of non-empirical publications.

In this analysis, biosimilars are differentiated from marketed 'intended copies' based on whether they meet the established rigorous regulatory requirements for biosimilarity as outlined by major regulatory health authorities such as the EMA, FDA, Health Canada, Pharmaceuticals Medical Devices Agency/Japan Ministry for Health Labour and Welfare (PMDA/MHLW), or the Korean Ministry of Food and Drug Safety (MFDS). Unless identified as an approved biosimilar or a marketed intended copy, all molecules presented in this review are considered development candidates (or 'proposed biosimilars'), with final determination of their status pending.

\subsection{Risk of Bias Assessment}

A risk of bias assessment was undertaken for each individual study using a validated tool matched to study type to assess the strength/validity of the empirical data in accordance with the preferred reporting items for systematic reviews and meta-analyses (PRISMA) guidelines [25, 26]. An assessment of the quality for the reporting of randomized controlled trials (RCTs) was carried out using 
recommendations from the UK National Institute for Health and Care Excellence (NICE) single technology appraisal (STA) manufacturer's template [27]. In addition, the Jadad scoring system was used for all included RCTs [28]. The quality of all included non-randomized/observational studies was assessed using the Downs and Black instrument [29]. As abstracts from conference proceedings report limited information on studies, the Downs and Black instrument was modified to include only the 12 most critical qualifying parameters (of 26) for quality assessment. Detailed parameters related to process were excluded as these data were not available in abstract formats, e.g., suitability of statistical method employed. Animal studies were assessed using the SYRCLE's Risk of Bias tool [30], and pharmacoeconomic studies were evaluated using Drummond's checklist for assessing economic evaluations [31].

\section{Results}

\subsection{Literature and Conference Search}

Results of the systematic search and screening of the biosimilars literature are presented in a PRISMA diagram $[32,33]$ for the empirical studies, with a separate designation in the diagram for non-empirical publications (e.g., commentaries, reviews, manufacturing/supply topics) (Fig. 1).

The search strategy yielded 1991 publications from the title and abstract screen, and those relevant to the topic of biosimilars (as defined by our criteria) were retained (768 publications in total). Of the 768 included publications, $244(32 \%)$ were identified as empirical publications, 491 (64\%) were non-empirical publications (i.e., review or opinion articles), and 33 (4\%) corresponded to payer or healthcare professional surveys. The number of publications is higher than the number of studies, as some studies were disseminated in more than one publication (Fig. 1).

The number of publications included in the analysis are presented in Fig. 2. Of the included references, 147 (19\%) reported $\mathrm{mAb}$ or fusion protein biosimilars for use in oncology and 301 (39\%) addressed biosimilars for the treatment of chronic inflammatory conditions. A total of 12 (2\%) publications were classified as 'other', and a further $465(61 \%)$ could not be classified by indication and were categorized as 'not specified'. A degree of overlap in the reported indications was also noted. For example, rituximab biosimilar publications were reported for both the oncology and inflammatory disorders categories, where relevant, as rituximab is indicated for both therapeutic areas.

\subsubsection{Empirical Publications}

Of the identified 244 empirical publications (and prior to data extraction), 64 (26\%) were classified as analytical, 55 $(23 \%)$ as nonclinical, and five $(2 \%)$ as 'other'. In total, 83 publications (34\%) reported RCTs, and 31 (13\%) were classified within the observational/post-marketing category; 13 (5\%) were relevant to health economics and seven reported both nonclinical and human clinical studies (Fig. 2). Since a handful of references included both nonclinical and human clinical data and were reported in more than one category, the publication counts do not sum to totals. Named biosimilars were identified in 90 unique studies (reported across 148 publications); 23 studies were reported in 36 publications in oncology, 55 studies (96 publications) in chronic inflammatory disease, ten studies (14 publications) in oncology and inflammatory diseases, and two studies (two publications) in 'other' diseases.

\subsubsection{Non-Empirical Publications}

Of the total number of included publications, 491 were categorized as non-empirical, of which 176 (36\%) were overview articles, 139 (28\%) covered regulatory issues and/or safety, 109 (22\%) were regarding development and production, and $54(11 \%)$ were related to market analysis and uptake and $13(3 \%)$ review or opinion articles covered other topics that were not classified (Fig. 2).

Within the overview category, the most common publications were 'general' overview articles ( $n=83$ [17\%]), and a further 74 publications provided an overview of a given therapy area ( $n=74$ [15\%]). The majority of publications on regulation and safety were concerned with regulatory and/ or policy topics ( $n=121$ [25\%]). Among the publications concerning development and production, most focused on biosimilar development ( $n=42$ [9\%]) or quality or analysis methods ( $n=43$ [9\%]). Market analysis and/or commercial uptake articles were predominantly concerned with economics or pricing $(n=21[4 \%])$ (Fig. 2).

\subsection{Named Biosimilars of Monoclonal Antibody (mAb) and Fusion Protein Originators Across Therapy Areas}

\subsubsection{Overview of Biosimilars in Development: Key Manufacturers}

In total, 21 different $\mathrm{mAb}$ or fusion protein originators were identified relevant to the topic of biosimilars (ESM Table S3). Figure 3 shows the number of molecules reported to be in development for each manufacturer classified by originator and therapy area. Across therapy areas, named biosimilars were reported for the following 
Fig. 1 PRISMA flow diagram showing the high-level breakdown of the publication counts. Where duplicates were retrieved for studies, originals (first published article) were retained if no additional data were provided in encore publications. If new data were identified, subsequent publications were included together with the original publication. This affected overall publication count but not overall study count. Note: Of the total 244 empirical publications, 90 empirical studies of named biosimilars or intended copies were identified, reported across 148 publications (23 studies in 36 publications in oncology, 55 studies in 96 publications in chronic inflammatory diseases, ten studies in 14 publications in oncology and chronic inflammatory diseases, two studies in two publications in 'other' diseases) and 96 empirical publications did not name the biosimilar being evaluated
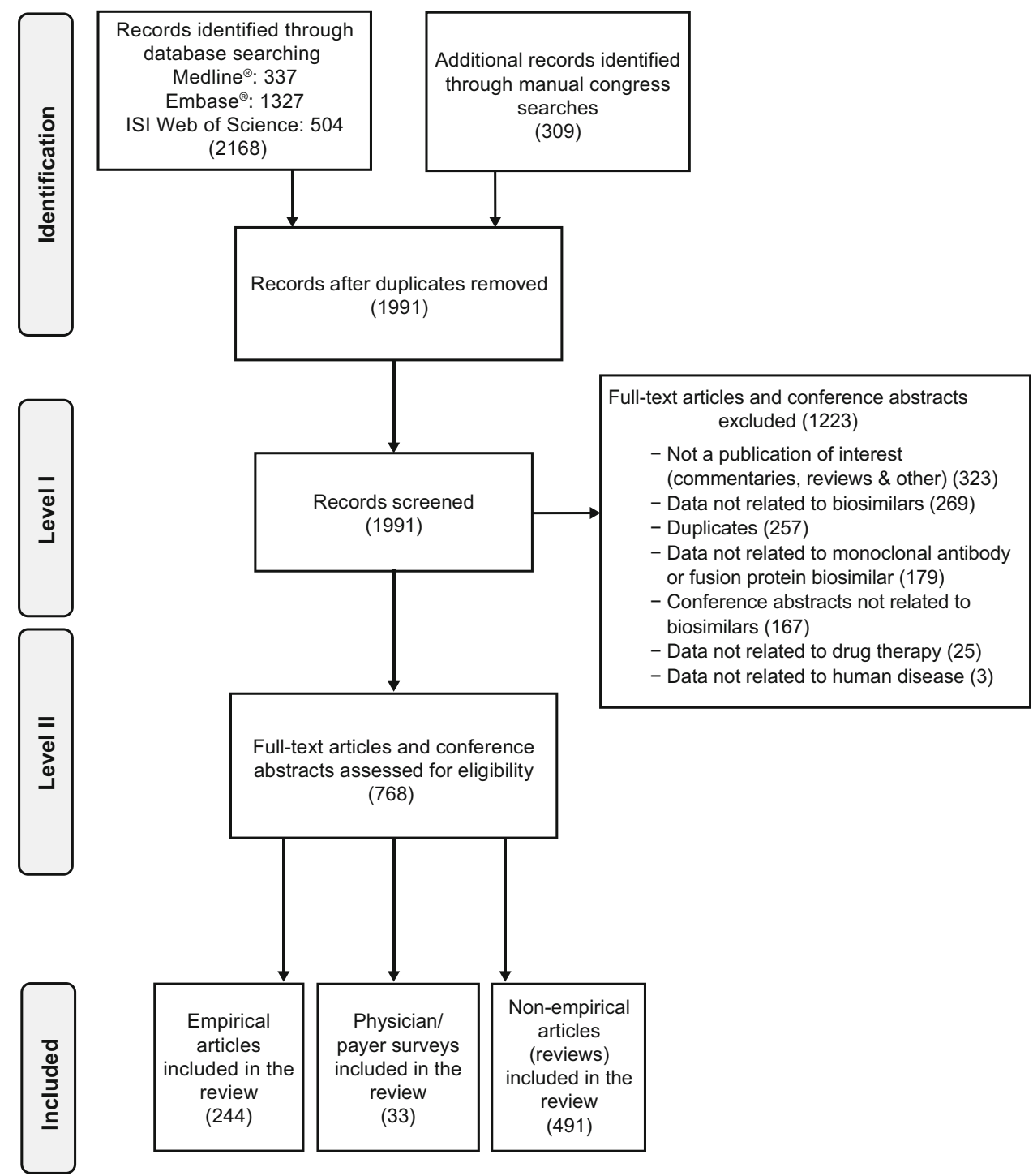

nine identified originators: adalimumab, abciximab, bevacizumab, etanercept, infliximab, omalizumab, ranibizumab, rituximab, and trastuzumab. Marketed intended copies were identified for etanercept and rituximab. In total, 43 named biosimilars (and a further four marketed intended copies) were identified from 27 different manufacturer/ development partnerships (Fig. 3).

\subsubsection{Biosimilars in Oncology}

For bevacizumab, four proposed biosimilars (ABP 215 [Amgen/Allergan], BCD-021 [Biocad], PF-06439535 [Pfizer], and RPH-001 [Alphamab]) were identified in empirical and non-empirical publications, of which ABP 215 was cited the most frequently, in two empirical studies reported across four publications. The following proposed trastuzumab biosimilars were reported: BCD-022 (Biocad), CTP6 (Celltrion/Hospira), FTMB/ABP 980 (Amgen/Synthon/
Allergan), and PF-05280014 (Pfizer), of which PF-05280014 was referenced the most frequently, in five empirical studies reported across 11 publications. Although the originator $\mathrm{mAb}$ cetuximab was referenced in empirical and non-empirical publications $(n=7$ and $n=2$, respectively), no named biosimilars were identified in these reports. Publications that did not disclose unique names of biosimilars were categorized as 'biosimilars without unique identifiers' (ESM Table S3).

\subsubsection{Biosimilars in Chronic Inflammatory Diseases}

Within the chronic inflammatory disease category, 14 different $\mathrm{mAb}$ or fusion protein originators were identified from the retrieved biosimilar publications. Named biosimilars were found for originators adalimumab, etanercept, and infliximab. For adalimumab, five proposed biosimilars were found: ABP 501 (recommended for FDA approval), ZRC-3197 
Fig. 2 Categorization of publication type. *Other category includes any other publication on the topic of biosimilars provided it is not one of the excluded empirical/ non-empirical publication types. Note: Publications were classified into the most relevant was more than one. Therefore, the number of publications classified into each therapeutic area category does not sum to the total number of publications. For example, overlap in licensed indications for originators/biosimilars led to multiple categorization. Among the empirical references, several $(n=7)$ include both nonclinical and human data, and as such have been classified into both categories. RCT randomized controlled trial category, which in some cases

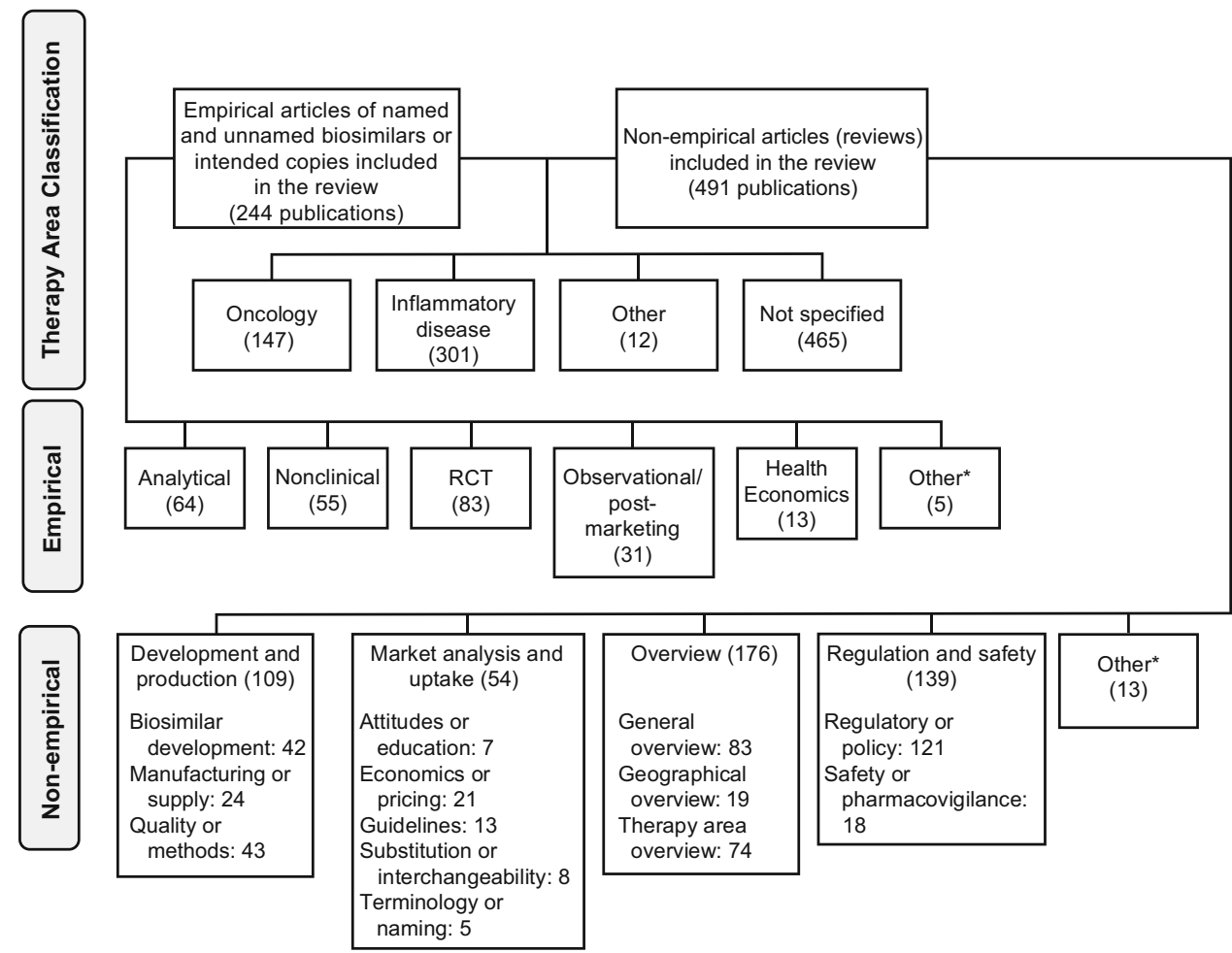

Allergan (USA)/Amgen (USA)/Synthon (The Netherlands) Alphamab (China)/R--Pharm (Russia) Amgen (USA) Avesthagen (India) Biocad (Russia) Boehringer Ingelheim (Germany) Cadila Healthcare (India) Celltrion (South Korea)/Hospira (USA) Center of Molecular Immunology (Cuba) Coherus Biosciences, Inc. (USA) Coherus Biosciences, Inc. (USA)/Daiicho Sankyo (Japan)/Baxalta (USA) Dr Reddy's Laboratories (India) Hanwha Chemical (South Korea)/Merck (USA) ISU ABXIS (South Korea) LG Life Sciences (South Korea) mAbxience (Switzerland) mAbxience (Switzerland)/Laboratorio Elea S.A.C.I.F. y A. (Argentina)/LIBBS (Brazil) Mycenax Biotech/TSH Biopharm Corp (Taiwan) National Engineering Research Center of Antibody Medicine (China) Pfenex (USA)/Hospira (USA) Pfizer (USA)

Probiomed (Mexico) Ranbaxy Laboratories (India)/Epirus Biopharmaceuticals (USA) Samsung (South Korea) Samsung Bioepis (South Korea) Sandoz (Switzerland) Shanghai CP Guojian Pharmaceutical (China)

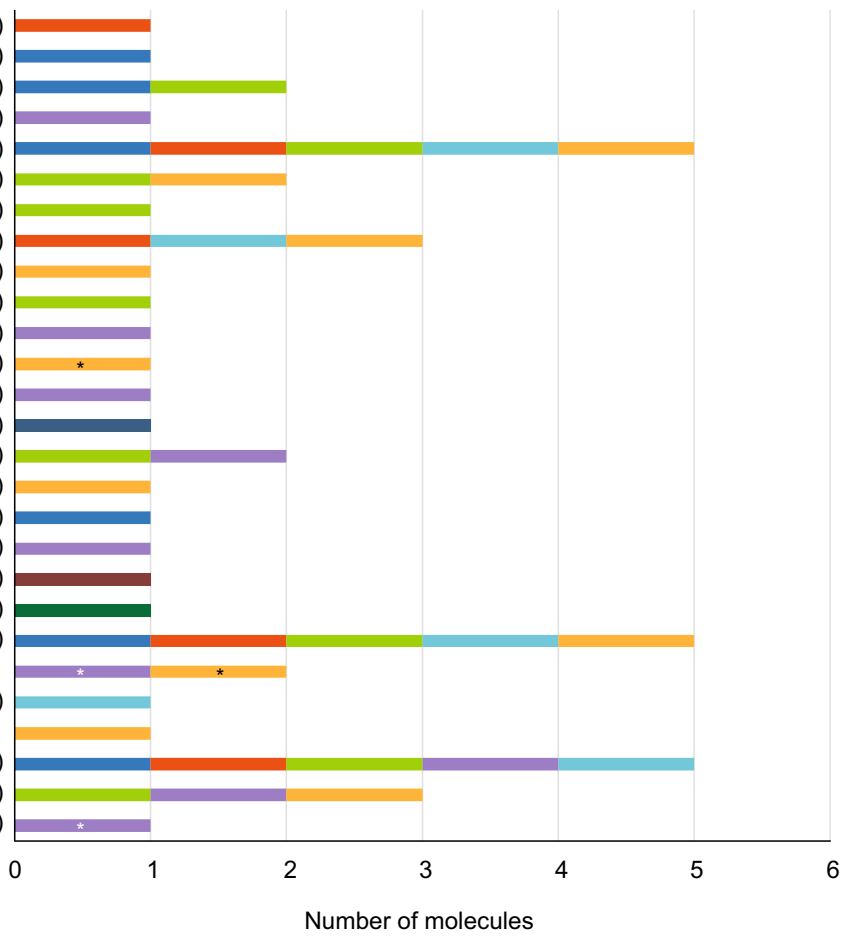

\footnotetext{
- Bevacizumab (oncology)

- Etanercept (chronic inflammatory diseases)

- Abciximab (other disease area)
}

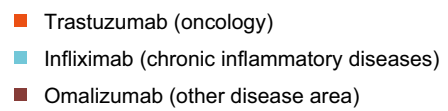

- Omalizumab (other disease area)

Adalimumab (chronic inflammatory diseases)

- Rituximab (oncology or chronic inflammatory diseases)

- Ranibizumab (other disease area)

Fig. 3 Biosimilar development pipeline: key manufacturers, country, and number of biosimilar agents categorized by originator and therapy area. Includes manufacturers with marketed intended copies (individual products indicated by an asterisk on the bar) 
(Exemptia ${ }^{\mathrm{TM}}$; Cadila Healthcare), GP2017 (Sandoz), PF-06410293 (Pfizer), and SB5 (Samsung Bioepis). ABP 501 was reported in four empirical studies, which were reported in seven empirical publications. GP2017 was evaluated in two studies, which were reported in three separate empirical publications. Four biosimilars were identified for infliximab: BOW015; (Ranbaxy Laboratories/Epirus Biopharmaceuticals; development now suspended), CT-P13 (EMA/FDA approved), PF-06438179 (Pfizer), and SB2 (EMA approved). Of these infliximab biosimilars, approved biosimilar CT-P13 was reported by far the most frequently (in 20 studies reported in 38 empirical publications and in 38 non-empirical publications). The following six biosimilars were identified for etanercept fusion protein: AVG01 (Avesthagen), ENIA11 (TuNEX ${ }^{\circledR} ;$ Mycenax Biotech/TSH Biopharm Corp), GP2015 (recommended for FDA approval), HD203 (Hanwha Chemical/Merck), LBEC0101 (LG Life Sciences), and SB4 (EMA approved) (ESM Table S3).

\subsubsection{Biosimilars in Both Oncology and Chronic Inflammatory Diseases}

Rituximab was identified in empirical and non-empirical publications (for either cancer or inflammatory conditions

Table 1 Biologic originator rituximab and corresponding named biosimilar agents in oncology and inflammatory disease classified by empirical study type ${ }^{\mathrm{a}}$

Biosimilar or IC (name ${ }^{\mathrm{b}}$, company)

\begin{tabular}{|c|c|c|c|c|c|}
\hline \multicolumn{6}{|c|}{ Reference counts for empirical publications (and studies) $^{c}$} \\
\hline RCT & $\begin{array}{l}\text { Observational/ } \\
\text { post-marketing }\end{array}$ & Nonclinical & Analytical & $\begin{array}{l}\text { Health } \\
\text { economics }\end{array}$ & Other \\
\hline
\end{tabular}

\section{Oncology/inflammatory disease mAbs}

1B8 (Center of Molecular Immunology, Cuba)

Onc: [113]

BCD-020 (AcellBia ${ }^{\mathrm{TM}}$; Biocad, Russia)

Onc: [38, 114, 115]

CT-P10 (Celltrion, South Korea)/Hospira, USA)

Inflamm: [83, 116]

GP2013 (Sandoz, Switzerland) ${ }^{\mathrm{d}}$

Onc: [49, 117-119]

Inflamm: [49, 117, 119]

PF-05280586 (Pfizer, USA) ${ }^{\mathrm{d}}$

Onc: [51, 120-122]

Inflamm: [51, 67, 120-127]

RTXM83 (mAbxience, Switzerland) ${ }^{\mathrm{d}}$

$\begin{array}{llll}- & - & \text { Onc: 1 (1) } \\ \text { Onc: } 3(1) & - & - & - \\ - & & & - \\ - & - & -\end{array}$

Onc: $1(1)$

Inflamm: 2 (1)

Onc: 4 (2) Onc: $4(2)$

Inflamm: 3 (2) Inflamm: 2 (2)

Onc: [41, 128]

Inflamm: [128]

SAIT101 (Samsung BioLogics, South Korea) ${ }^{\mathrm{d}}$ [44] Onc: 1 (1)

IC of rituximab

Kikuzubam $^{\circledR}$ (IC) (Probiomed, Mexico) ${ }^{\mathrm{d}}$

Onc: [90]

Inflamm: $[66,90]$

Reditux $^{T M}$ (IC) (Dr. Reddy's Laboratories, India) ${ }^{\mathrm{d}} \quad$

Onc: [36, 37, 39, 46, 90, 129-133]

Inflamm: [39, 62, 65, 90, 129-131, 134]

Biosimilars without unique identifiers

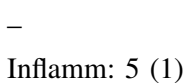

Onc: 1 (1)

$$
-
$$

$-$

Onc: 1 (1)

Inflamm: 1 (1)

Onc: 1 (1)

Onc: 4 (2) Onc: 4 (2)

Inflamm: 6 (3) Inflamm: 5 (2)

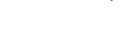

$-$

Inflamm: 1 (1) Inflamm: 1 (1) Inflamm: 1 (1)

Onc: 5 (3) Onc: 3 (3) Onc: 3 (3)

Inflamm: 4 (3) Inflamm: 1 (1) Inflamm: 3 (3)

Corresponding indications for study counts for rituximab are labelled with 'Onc' for oncology and 'Inflamm' for chronic inflammatory disease IC intended copy, $m A b s$ monoclonal antibodies, $R C T$ randomized controlled trial

${ }^{a}$ Italic font indicates biosimilars that are included in at least one reference naming multiple biosimilars

b Alternative names for biosimilars are provided where applicable

c Reference counts correspond to the number of identified publications. The number of unique empirical studies reported for named biosimilars is shown in parentheses

${ }^{\mathrm{d}}$ Several studies/publications were classified under both oncology and inflammatory disease indications or the disease area was not specified 
or, in some cases, for combined indications). Among the rituximab biosimilar publications, seven proposed biosimilars were referenced (the majority in empirical publications): 1B8 (Center of Molecular Immunology, Cuba), BCD-020 (Biocad), CT-P10 (Celltrion/Hospira), GP2013 (Sandoz), PF-05280586 (Pfizer), RTXM83 (mAbxience), and SAIT101 (Samsung BioLogics). For the proposed biosimilars of rituximab, PF-05280586 was most often reported (ESM Table S3), with published data available for two oncology studies (four publications) and five chronic inflammatory disease studies (ten publications).

\subsubsection{Biosimilars in Other Disease Areas}

Within the 'other' disease area category (including cardiovascular disorders, respiratory [allergic] conditions, and eye conditions), three proposed biosimilars, clotinab (ISU ABXIS), CMAB007 (National Engineering Research Center of Antibody Medicine), and PF582 (Pfenex/Hospira), were identified for abciximab (cardiovascular), omalizumab (respiratory/asthma), and ranibizumab (ophthalmology), respectively. Clotinab and CMAB007 were each reported in one empirical study, and PF582 was reported once in a non-empirical publication (ESM Table S3).

\subsection{Empirical Publications in Oncology}

The reference counts for empirical studies and publications for identified originators in oncology, along with corresponding proposed biosimilars, are shown in Fig. 4. As rituximab is licensed for oncology and chronic inflammatory conditions, the analyses are presented separately. Pfizer's PF-05280014 (trastuzumab) was the most commonly reported proposed biosimilar in oncology (Fig. 4), reported in seven RCT publications (for three unique RCT studies), five nonclinical publications (covering two unique studies), and four analytical publications (describing two unique studies). The second most frequently reported biosimilar was ABP 215, a proposed bevacizumab biosimilar, identified in two RCT publications (one study), four nonclinical publications (two studies), and one analytical publication describing a single study.

At study cut-off, all biosimilars except RPH-001 (Alphamab, China/R-Pharm, Russia) and PF-06439535 had entered into clinical stages of development, with published RCT data available in at least one study. Interestingly, despite entering into clinical development programs, published analytical and nonclinical data were not available for BCD-021, BCD-022, CT-P6, or FTMB/ ABP 980.

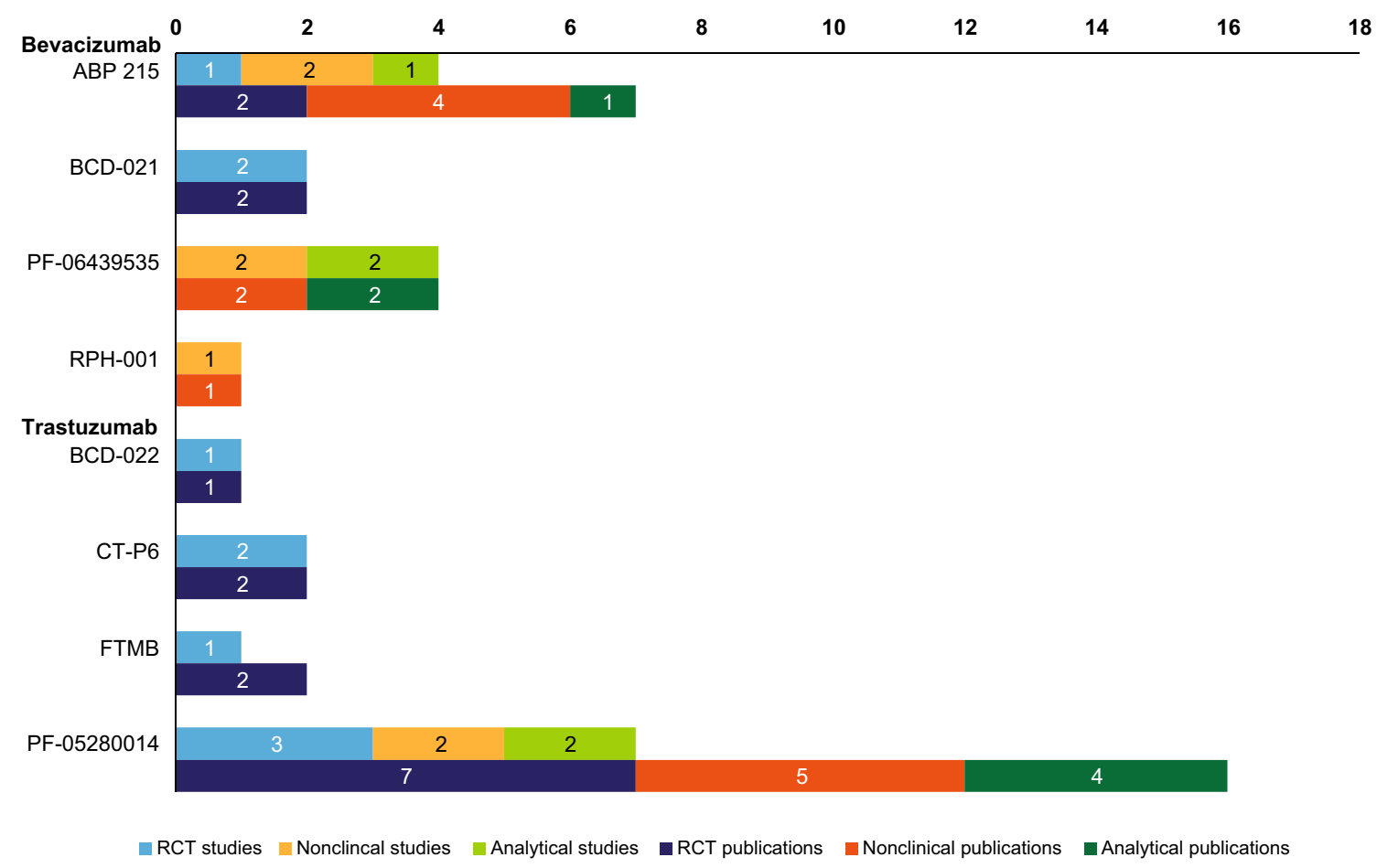

Fig. 4 Frequency of reported named biosimilars in oncology. Excludes data (shown in Table 1) on biosimilars or intended copies of rituximab. $R C T$ randomized controlled trial 


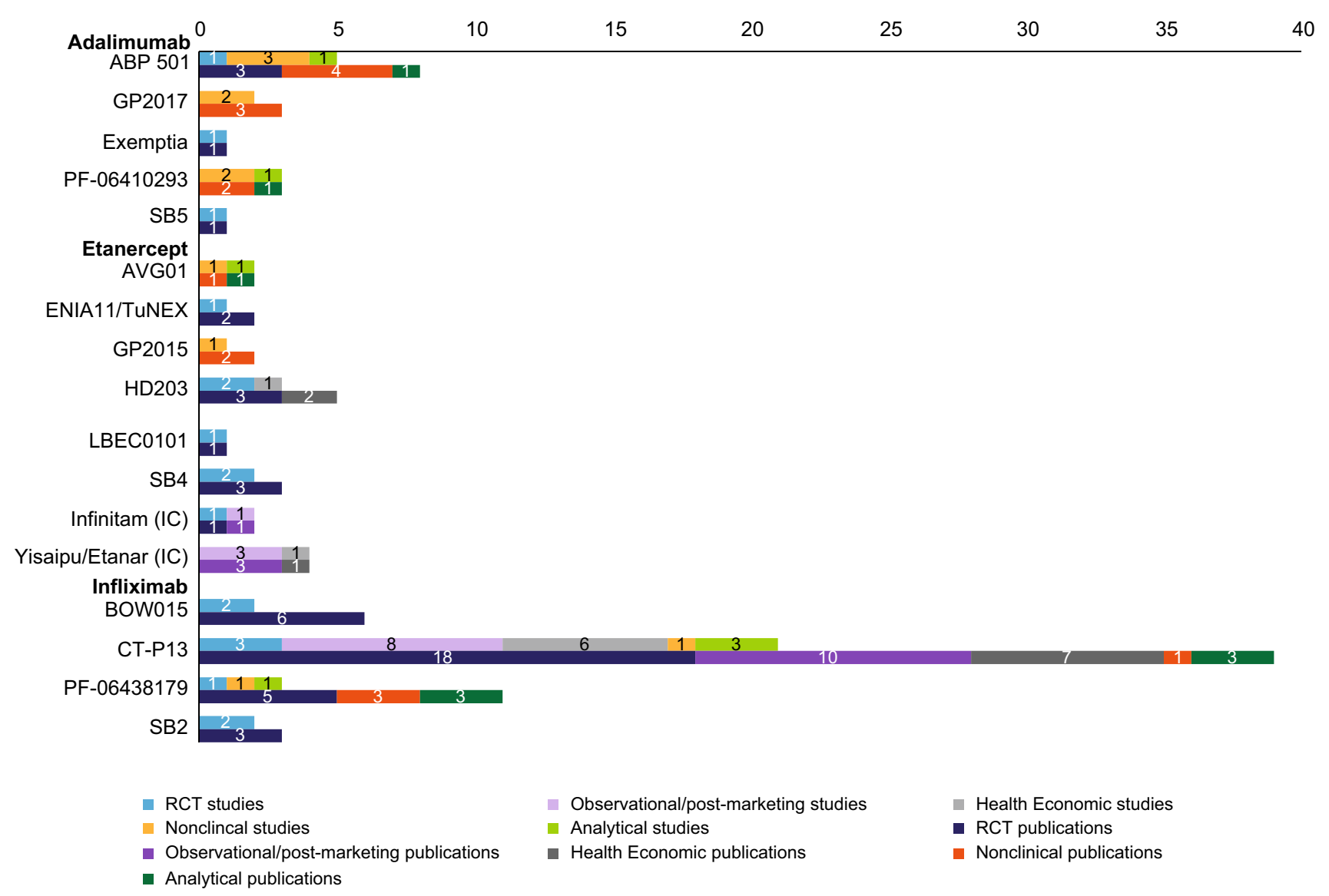

Fig. 5 Frequency of reported named biosimilars and intended copies in chronic inflammatory diseases. $I C$ intended copy, $R C T$ randomized controlled trial

\subsection{Empirical Publications in Chronic Inflammatory Diseases}

The reference counts for empirical studies and publications for identified originators in chronic inflammatory disease, along with corresponding biosimilars, are shown in Fig. 5. Of the biosimilars indicated for chronic inflammatory conditions (namely biosimilars of adalimumab, etanercept, and infliximab), Celltrion's CT-P13 was the most commonly reported, across all stages of development.

A total of 18 RCT publications (reporting three unique RCT studies) and ten observational/post-marketing publications (eight studies) were identified for CT-P13. During the study period, CT-P13 was evaluated in one nonclinical study, three analytical studies, and in six health economic studies. Several proposed biosimilars for chronic inflammatory diseases (namely SB5, ENIA11, and LBEC101 (LG Life Sciences, South Korea); etanercept) had entered into clinical development stages with published PK/safety data in healthy subjects, without published data from preclinical (analytical, functional, or nonclinical) studies. Furthermore, ZRC-3197, HD203, SB4, BOW015, and SB2 all had published data from $\mathrm{PK} / \mathrm{safety}$ studies and/or comparative safety/efficacy trials (in RA), without underlying published data or evidence to suggest that they demonstrate similar structural or functional resemblance to that of their originators.

\subsection{Empirical Publications on Biosimilars of Rituximab for Both Oncology and Inflammatory Diseases}

PF-05280586 was the highest reported molecule, in five RCT publications (one study), six nonclinical publications (two studies applicable to the oncology indication and three studies applicable to inflammatory disease), and five analytical publications (two studies applicable in both therapy areas) (Table 1). BCD-020, RTXM83, and SAIT101 have all been evaluated in RCTs for oncology only, with published data available for just one RCT each to date. For RCTs in chronic inflammatory disease, CT-P10 and PF-05280586 have both been evaluated in a single study. Of the seven identified rituximab biosimilars, only four (namely, 1B8, GP2013, PF-05280586, and RTXM83) had undergone head-to-head analytical and nonclinical assessments with originator rituximab. The comprehensive 
analytical data, upon meeting the scientific rigors of similarity assessment outlined by the EMA and FDA, can be used to extrapolate to either oncology or chronic inflammatory disease indications.

\subsection{Empirical Publications in Other Disease Areas}

Only three proposed biosimilars were identified in this category: clotinab, a biosimilar of abciximab (for cardiovascular disorders); CMAB007, a biosimilar of omalizumab (for respiratory conditions); and PF582, a ranibizumab biosimilar for ophthalmologic conditions (Table 2).

Generally, published empirical studies for biosimilars in other disease areas are scarce. To date, very little RCT or preclinical data have been published to support the use of these proposed biosimilars for these indications. Two empirical studies (both clinical PK/safety investigations), were identified for CMAB007 and clotinab.

\subsection{Published or Ongoing Comparative Clinical Studies}

Since demonstration of biosimilarity for FDA or EMA approval requires rigorous comparison with the originator molecule, the majority of the identified empirical studies compared some aspect of a biosimilar with its originator molecule - a finding that was apparent across all study types and in all therapy areas. A number of studies have also compared the biosimilar of interest with the originator from both US and EU sources across oncology and chronic inflammatory disease areas. To facilitate comparisons across molecules and to highlight gaps in the evidence base, Table 3 presents a summary of all of the comparative, $\mathrm{PK} /$ safety, safety/efficacy, and post-marketing/observational studies identified for each molecule.
Within oncology, all of the identified proposed biosimilars with the exception of RPH-001 (Alphamab/R-Pharm) were either undergoing or had completed comparative PK/ safety studies or comparative efficacy/safety trials versus bevacizumab at the time of analysis.

For the proposed trastuzumab biosimilars (BCD-022, CT-P6, FTMB/ABP 980, PF-05280014, and SB3 [Samsung Bioepis]), a number of comparative PK/safety or safety/efficacy trials were either ongoing or complete with published data versus trastuzumab at the time of analysis.

For the rituximab biosimilars being investigated within oncology, published comparative data from PK/safety or safety/efficacy trials versus rituximab were reported for RTXM83, SAIT101, and BCD-020, respectively. At the time of review, ongoing comparative safety/efficacy trials were reportedly also underway for BCD-020, CT-P10, GP2013, PF-05280586, and RTXM83.

In chronic inflammatory diseases, a number of comparative safety/efficacy trials for the rituximab biosimilars BCD-020, BI 69550 (Boehringer Ingelheim), and CT-P10 were reported as ongoing (but without published data at the time of analysis). Published comparative PK/safety trials in patients with RA were published for CT-P10 and PF-05280586.

Among the adalimumab, etanercept, and infliximab biosimilars, efficacy/safety data in RA versus the originator were published for ZRC-3197, HD203, SB4, BOW015, CT-P13, and SB2.

Comparative safety/efficacy trials were reportedly ongoing (with no publications to date) for a number of adalimumab biosimilars in chronic inflammatory diseases (Table 3). Comparative PK/safety evaluations were also reportedly underway for adalimumab biosimilars BCD-057 (Biocad), LBAL (LG Life Sciences), PF-06410293, and SB5 at the time of analysis.

Table 2 Originator monoclonal antibodies and corresponding named biosimilar agents in other disease areas classified by empirical study type

\begin{tabular}{|c|c|c|c|c|c|c|c|}
\hline \multirow{2}{*}{$\begin{array}{l}\text { Biologic } \\
\text { originator }^{\mathrm{a}}\end{array}$} & \multirow[t]{2}{*}{ Biosimilar (name ${ }^{\mathrm{b}}$, company) } & \multicolumn{6}{|c|}{ Reference counts for empirical publications (and studies) ${ }^{\mathrm{c}}$} \\
\hline & & RCT & $\begin{array}{l}\text { Observational/post- } \\
\text { marketing }\end{array}$ & Nonclinical & Analytical & $\begin{array}{l}\text { Health } \\
\text { economics }\end{array}$ & Other \\
\hline Abciximab & Clotinab (ISU ABXIS) [88] & $1(1)$ & - & - & - & - & - \\
\hline Omalizumab & $\begin{array}{l}\text { CMAB007 (National Engineering Research Center } \\
\text { of Antibody Medicine, China) [89] }\end{array}$ & $1(1)$ & - & - & - & - & - \\
\hline Ranibizumab & PF582 (Pfenex, USA/Hospira, USA) & - & - & - & - & - & - \\
\hline
\end{tabular}

$m A b s$ monoclonal antibodies, $R C T$ randomized controlled trial

a Abciximab is indicated for cardiovascular disorders, omalizumab is indicated for respiratory (allergic) conditions, ranibizumab is indicated for eye conditions (ophthalmology)

b Alternative names for biosimilars are provided where applicable

${ }^{c}$ Reference counts correspond to the number of identified publications. The number of unique empirical studies identified is indicated in parentheses 


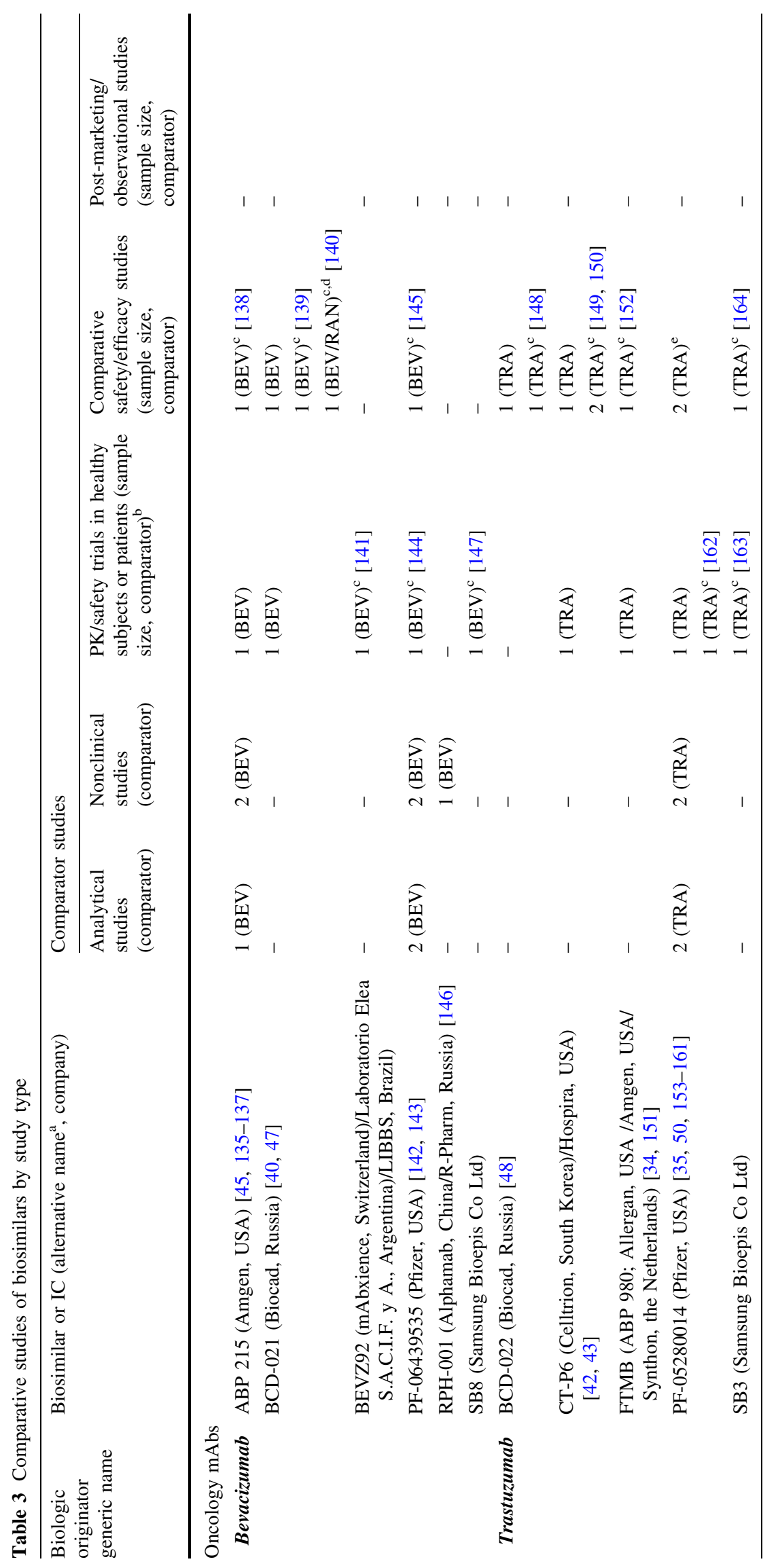




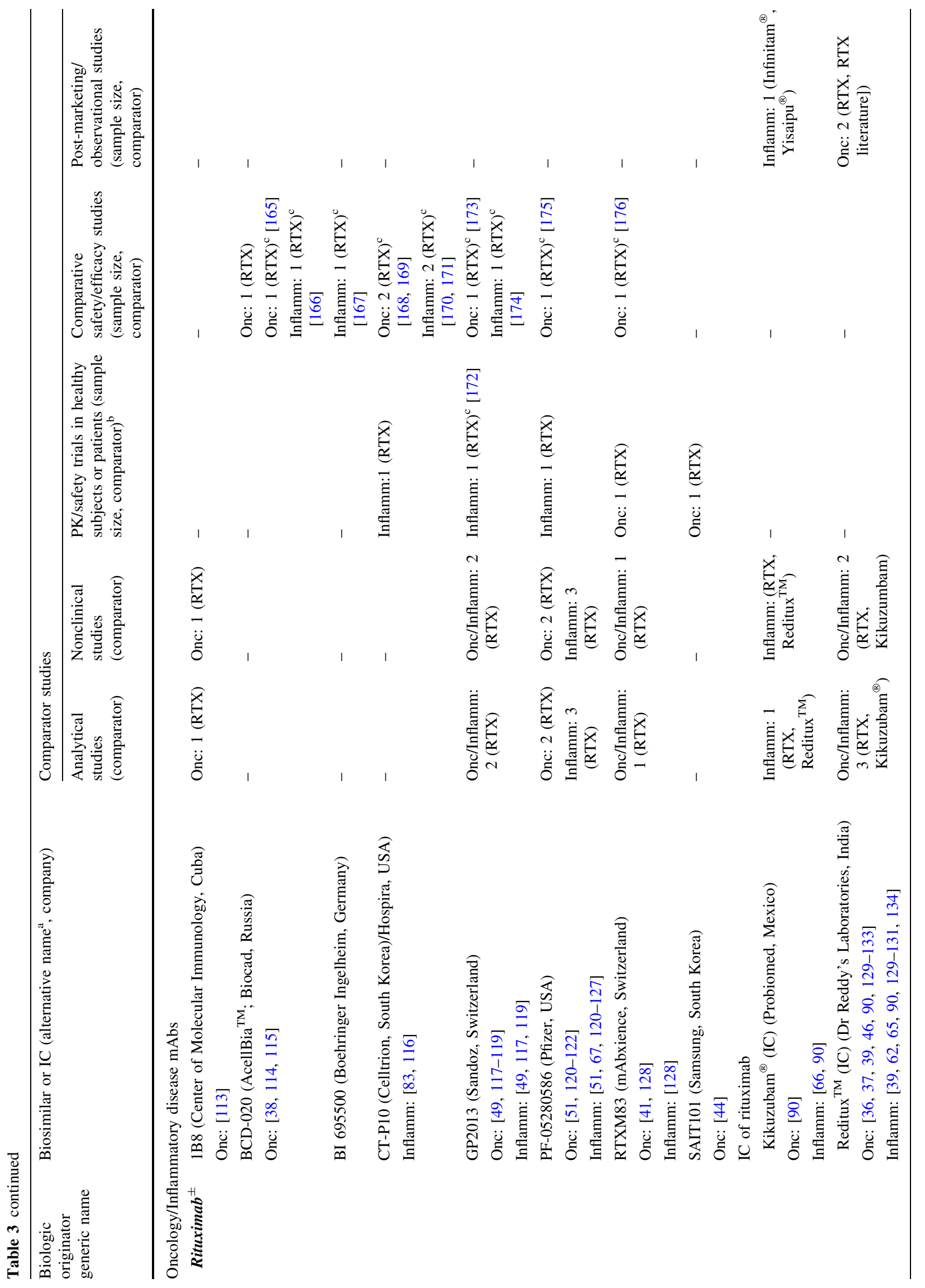




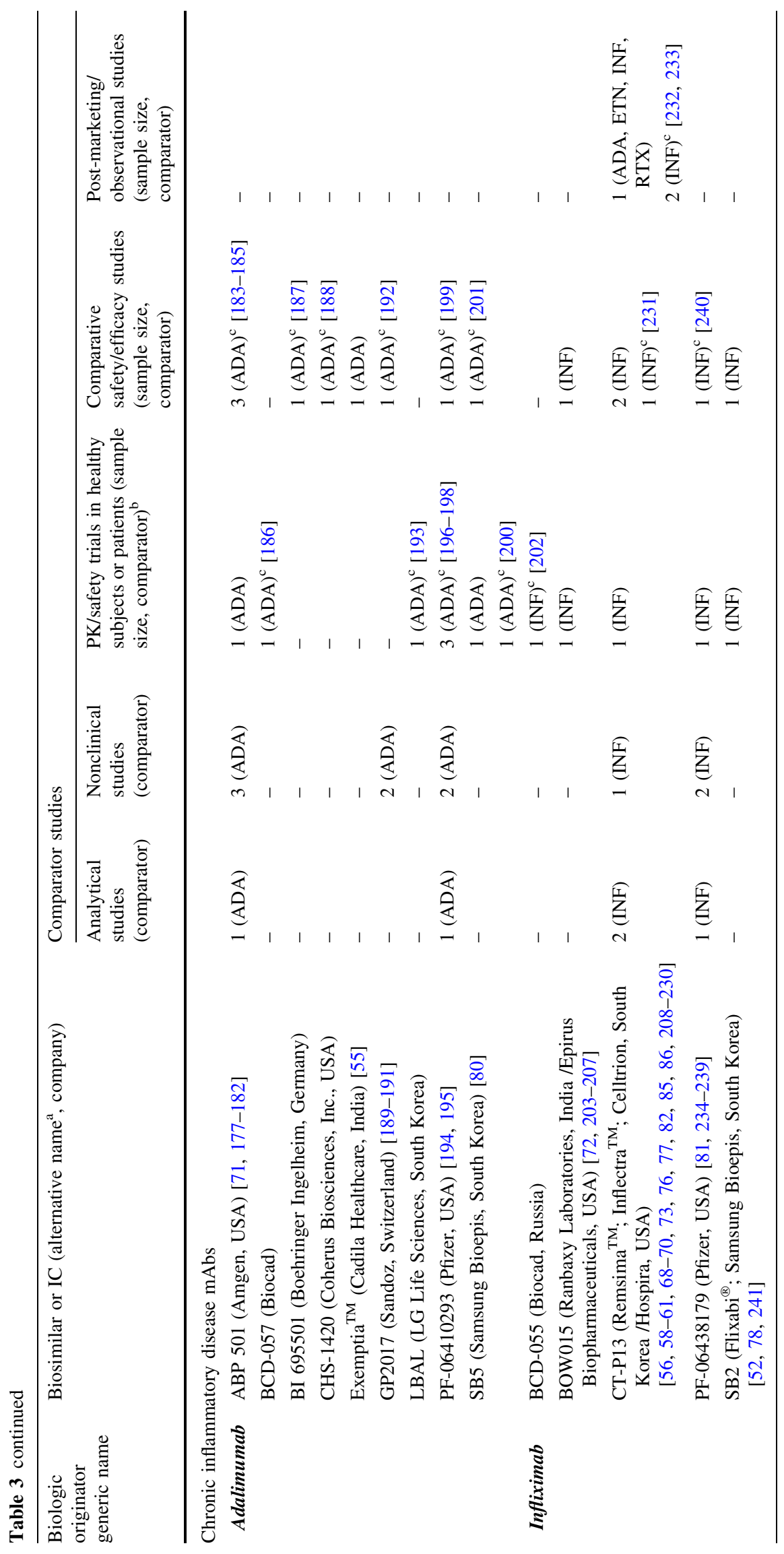




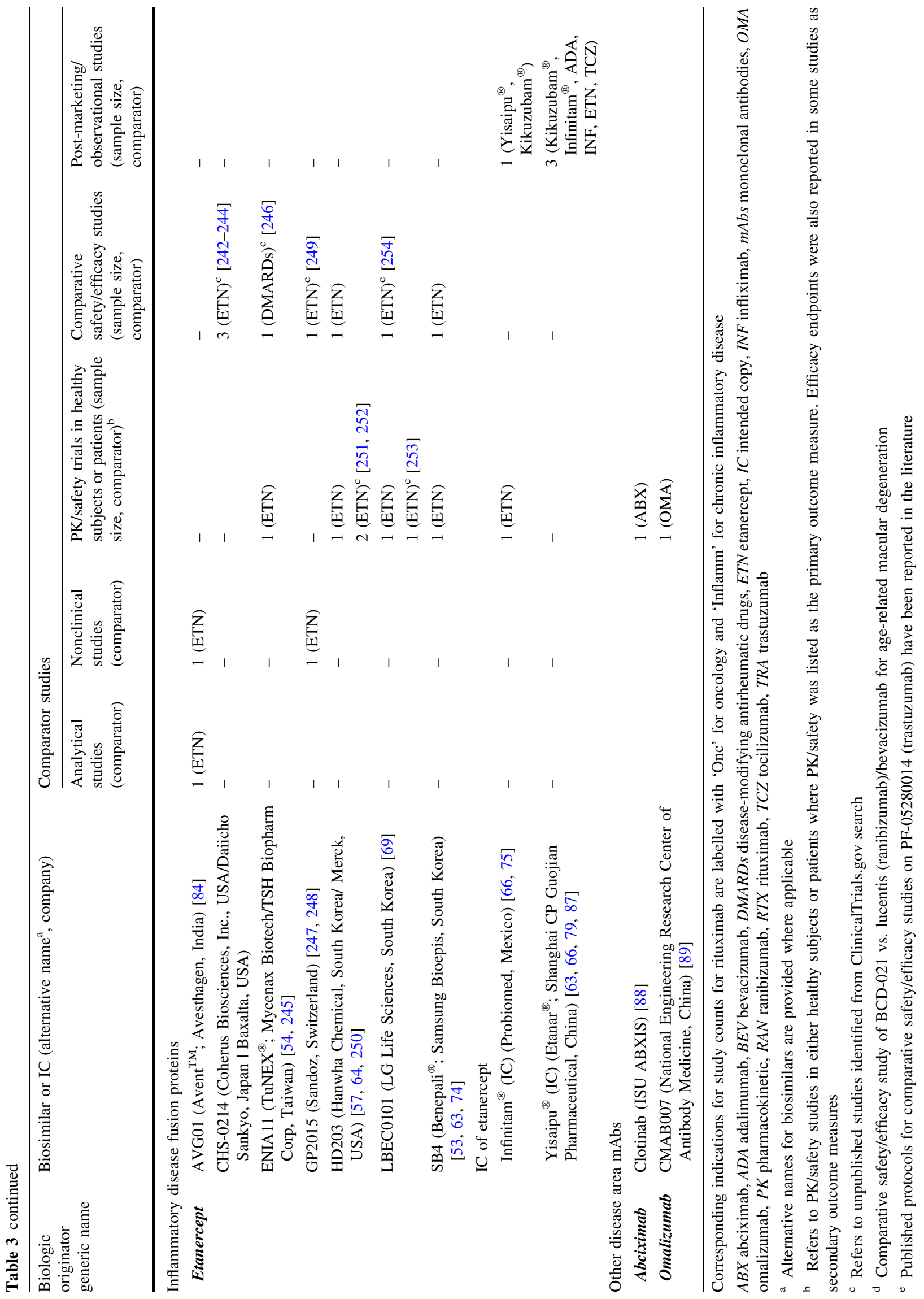


The etanercept biosimilars ENIA11, HD203, LBEC0101, and SB4 all had published comparative PK/ safety data. Comparative efficacy/safety studies were reported as still active or completed for CHS-0214 (Coherus Biosciences/Daiicho Sankyo/Baxalta), ENIA11 (vs. disease-modifying anti-rheumatic diseases [DMARDs]), GP2015, and LBEC0101.

Among infliximab biosimilars, comparative efficacy/ safety trials were reported as ongoing for CT-P13 and $\mathrm{PF}-06438179$. A comparative PK/safety trial of BCD-055 (Biocad) in ankylosing spondylitis was also identified in the search of ClinicalTrials.gov. At the time of the review, no published data had been retrieved for BCD-055.

Unsurprisingly, at the analysis cut-off, approved biosimilar CT-P13 had the greatest number of published studies (one clinical PK/safety, two clinical safety/efficacy), with a further study (clinical safety/efficacy) listed in ClinicalTrials.gov but not published at the time of review.

The findings additionally demonstrate a significant body of past or ongoing clinical trial activity for biosimilars in development across both oncology and chronic inflammatory disease areas, particularly for trastuzumab biosimilars CT-P6 and PF-05280014 and for adalimumab biosimilars ABP 501 and PF-06410293, respectively.

A detailed evaluation of the findings across all of these studies will be presented as part of a separate analysis of biosimilars for the treatment of chronic inflammatory diseases and cancer (Jacobs et al. 2016b [submitted]; Jacobs et al. 2016c [manuscript in preparation]).

\subsection{Intended Copies}

Empirical data on marketed intended copies of etanercept (Yisaipu ${ }^{\circledR}\left[\right.$ Etanar $^{\circledR}$; Shanghai CP Guojian Pharmaceutical], Infinitam ${ }^{\circledR}$ [Probiomed]) and rituximab (Kikuzubam ${ }^{\circledR}$ [Probiomed], Reditux ${ }^{\mathrm{TM}}$ [Dr. Reddy's Laboratories]) were identified in the published literature (Table 1; Fig. 5; ESM Table S3).

Yisaipu ${ }^{\circledR}$ was reported in four studies described in four empirical publications (Fig. 5; ESM Table S3). Infinitam ${ }^{\circledR}$ was investigated in two studies reported in two publications (Fig. 5; ESM Table S3).

Kikuzubam $^{\circledR}$ was reported in a single study in oncology (one publication) and in two independent studies (two publications) in chronic inflammatory disease (Table 1; ESM Table S3). Reditux ${ }^{\mathrm{TM}}$ was referenced in eight oncology studies (in ten publications) and seven inflammatory disease studies (in eight publications) (Table 1; ESM Table S3).

In summary, most comparative studies reported for intended copies were either analytical/nonclinical or observational in nature, with only a single RCT identified for Infinitam ${ }^{\circledR}$ (Table 3). Suffice to say, significant evidence gaps remain with respect to the efficacy and safety of intended copies for the treatment of cancer and chronic inflammatory diseases based on the published information currently available.

\subsection{Risk of Bias Assessments for Empirical Studies}

\subsubsection{Oncology Studies}

Two RCTs [34, 35] were evaluated using the NICE STA template and Jadad scoring tool (ESM Fig. S1). Both studies were considered excellent quality. Two observational studies [36, 37] were assessed using the Downs and Black scoring tool (ESM Fig. S2). Both were considered good quality. Since abstracts generally provide limited information on study methodologies and outcomes, the Downs and Black instrument was adapted to assess the quality of the 11 identified abstracts for original studies [38-48]. The total score was fair quality (3-4) for one study [39], good quality (5-8) for two studies [41, 46], and excellent quality (9-12) for eight studies [38, 40, 42-45, 47, 48] (ESM Fig. S3). The majority of studies published as conference abstracts were of good or excellent quality (90.9\%). Three animal studies were assessed using SYRCLE's risk of bias tool [49-51] (ESM Fig. S4) and found to be of moderate quality. Nonclinical abstract publications and cell-based or analytical studies were not assessed for risk of bias, as validated risk of bias assessment tools for these types of studies and publications were unavailable at the time of analysis.

\subsubsection{Chronic Inflammatory Disease Studies}

Seven RCTs were assessed using the NICE STA manufacturer's template and Jadad scoring tool [52-58], and all were considered excellent quality (ESM Fig. S1). Four observational studies were assessed using the Downs and Black scoring tool [59-62] and considered to be of fair quality (ESM Fig. S2). The modified Downs and Black instrument was used to assess the quality of the 22 identified abstracts for original studies [39, 63-83], with scores of fair quality (3-4) for four studies [39, 66, 70, 76], good quality (5-8) for seven studies [63, 65, 67, 68, 73, 77, 79], and excellent quality (9-12) for 11 studies [64, 69, 71, 72, 74, 75, 78, 80-83] (ESM Fig. S3). The majority of studies published as conference abstracts were of good or excellent quality $(81.8 \%)$. Three animal studies were assessed using SYRCLE's risk of bias tools [49, 51, 84] and found to be of moderate quality (ESM Fig. S4). Three health economic studies were assessed using Drummond's checklist for assessing economic evaluations [85-87] and considered good quality (ESM 
Fig. S5). As with studies identified for oncology, nonclinical abstract publications and cell-based or analytical studies were not assessed for risk of bias.

\subsubsection{Other Disease Area Studies}

Two RCTs were assessed using the NICE STA manufacturer's template and Jadad scoring tool $[88,89]$; both were considered good quality (ESM Fig. S1).

\subsection{Weight and Breadth of Evidence for Biosimilarity}

Regulatory authorities (e.g., FDA) base their final determination of biosimilarity between the proposed biosimilar and the originator on the totality of the data submitted by the biosimilar manufacturer for consideration. The authors of this review did not attempt to assess the agents against the criteria used by regulatory authorities, but instead based their analysis on the totality of evidence in the public domain with biosimilarity determined on the basis of investigators' conclusions.

In this analysis, the total number of studied variables (from identified analytical/nonclinical studies) and total reported patient numbers (from clinical studies) were extracted and then mapped (Fig. 6a, b) against the 'degree of similarity' (as observed by the study investigator). This was to demonstrate the depth of the research programs and the relative weight of supporting evidence available for each agent. The number of studied variables and the number of patients enrolled was not a factor in the determination of biosimilarity.

Molecules were mapped on a grid to illustrate relative positioning. For the $\mathrm{x}$-axis, the degree of similarity was ranked using the investigator assessment of individual clinical (Fig. 6a), analytical and nonclinical variables (Fig. 6b). As an example, for PF-05280014, a proposed biosimilar for trastuzumab, analytical and nonclinical data were reported by investigators to be either similar or identical (i.e., superimposable) across all variables assessed. The positioning of PF-05280014 on the grid reflects this. In contrast, Flores-Ortiz et al. [90], noted the mass spectrometry and cation exchange data were heterogeneous for the intended copy Kikuzubam ${ }^{\circledR}$ in comparison with its rituximab originator, while other variables (differential scanning calorimetry analysis, peptide mapping, glycan quantification, etc.) were reported to be the same. Thus, the positioning of Kikuzubam ${ }^{\circledR}$ was determined to be both dissimilar and identical across selected variables. Kikuzubam ${ }^{\circledR}$ is the only molecule in this review that exhibited such heterogeneity.

Based on clinical reports (Fig. 6a), development candidates FTMB, RTXM83, and HD203 were reported to be similar to their originators. Intended copy Yisaipu ${ }^{\circledR}$ was also considered by investigators to be similar. On the basis of clinical studies, investigators found all other development candidates and intended copies to be highly similar.

Investigators deemed a few molecules not to have met biosimilarity criteria, at the time of reporting. Based on preclinical reports (Fig. 6b), development candidate ABP 501 was determined to be dissimilar with respect to carbohydrate structure. Intended copies Reditux ${ }^{\mathrm{TM}}$ and Kikuzubam $^{\circledR}$ (refer to Fig. 6 footnote) were also reported to be dissimilar on the basis of a number of analytical and nonclinical variables.

The body of evidence for biosimilar use in human subjects from clinical studies is growing, with a high proportion reporting patient samples of more than 100 . Seven proposed biosimilars have published clinical data on fewer than 100 human subjects (namely BCD-020, BCD-022, LBEC0101, SAIT101, ENIA11, RTXM83, and clotinab), while CT-P13 and PF-05280014 have published studies involving more than 1000 human subjects (which for PF-05280014, includes patients from two published study protocols, with an estimated pooled enrollment of $N=910$ ) (Fig. 6a).

When considering the breadth of data available for preclinical studies for named biosimilars (based on number of variables reported from structural, functional, and nonclinical studies), the amount of reported information available across studies was inconsistent (Fig. 6b). More investigated variables for analytical and nonclinical biosimilarity (ranging from 29 to 54) were published for PF-05280586, PF-05280014, and GP2013. The remaining agents published an average of only five variables across their preclinical programs, as reported in the literature. Although the investigators concluded that the majority of molecules exhibited biosimilarity to their originator, it is worth noting that comparative data were not provided for all attributes studied.

\subsection{Non-Empirical Publication Classifications for Originators or Named Biosimilars}

A significant number of non-empirical biosimilar publications on topics concerning 'development and production', 'market analysis and uptake', 'regulation and safety', or general 'overview' review articles referenced originators without citing named biosimilars (Table 4). The majority of non-empirical publications cited originators for chronic inflammatory diseases without reference to named biosimilars (Table 4).

Publications focusing on development and production were mainly concerned with biosimilar development, manufacturing or supply processes, or quality and analytical methods. Publications categorized under 'market 

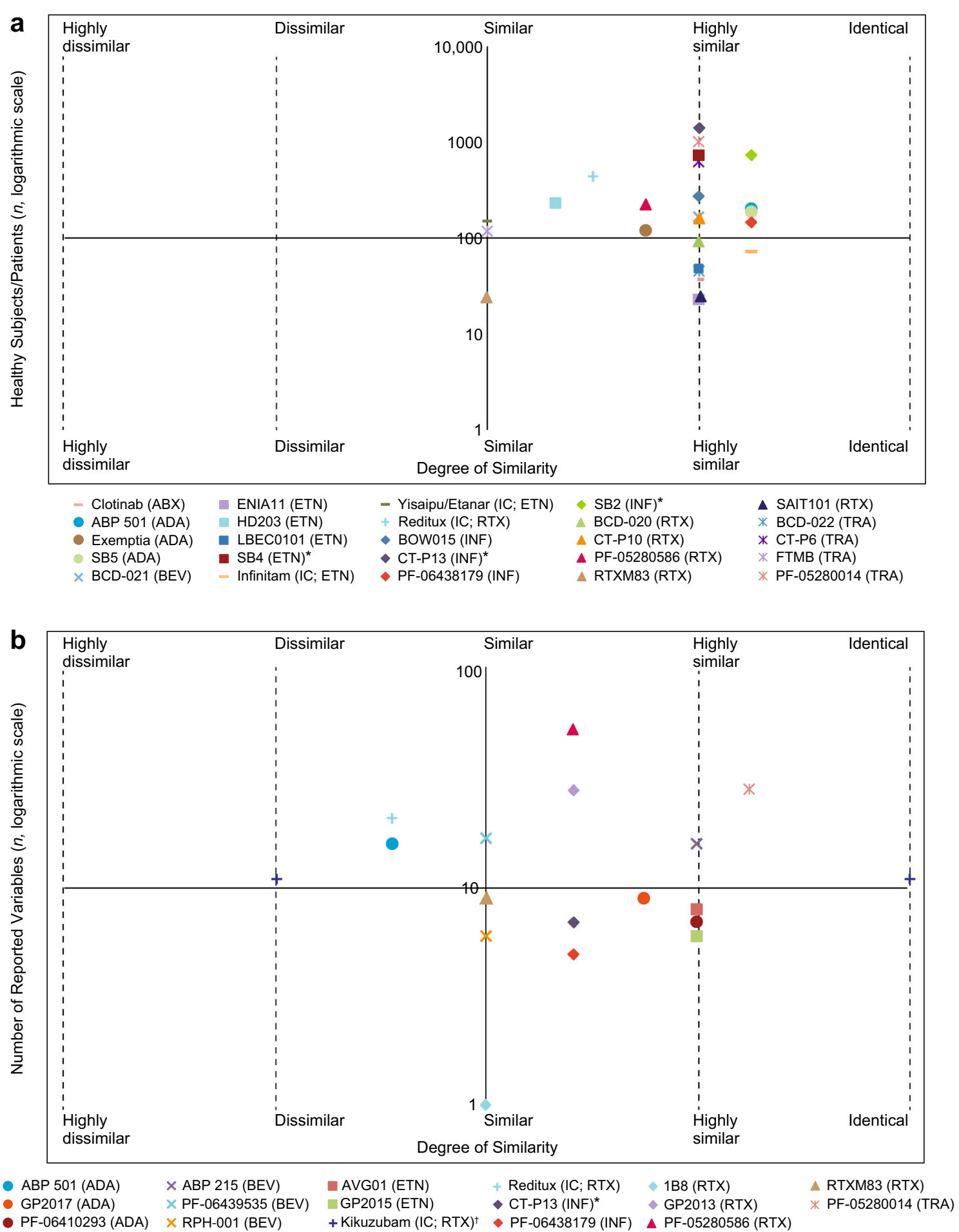

Fig. 6 Biosimilarity and a total treated patients for named biosimilars in clinical trials, $\mathbf{b}$ breadth of data for named biosimilars in analytical and nonclinical studies. 'Degree of similarity' for biosimilars and intended copies is inferred from the totality of evidence provided from all available published studies (up to 3 September 2015) and is based on the original conclusions made by the study investigators. The scale of reference used by each investigator was not accounted for, as not uniformly reported. *Agents that have already met the European Medicines Agency and/or US FDA requirements and have been approved as biosimilars. 'Based on author interpretation of study data, Kikuzubam ${ }^{\circledR}$ purportedly exhibits some highly dissimilar and some identical physicochemical characteristics compared with the originator. PF-05280014 had two published study protocols at the time of analysis with a combined enrollment of $N=910$ and a published study in 105 healthy subjects. $A B X$ abciximab, $A D A$ adalimumab, $B E V$ bevacizumab, $E T N$ etanercept, $I C$ intended copy, INF infliximab, $R T X$ rituximab, TRA trastuzumab 


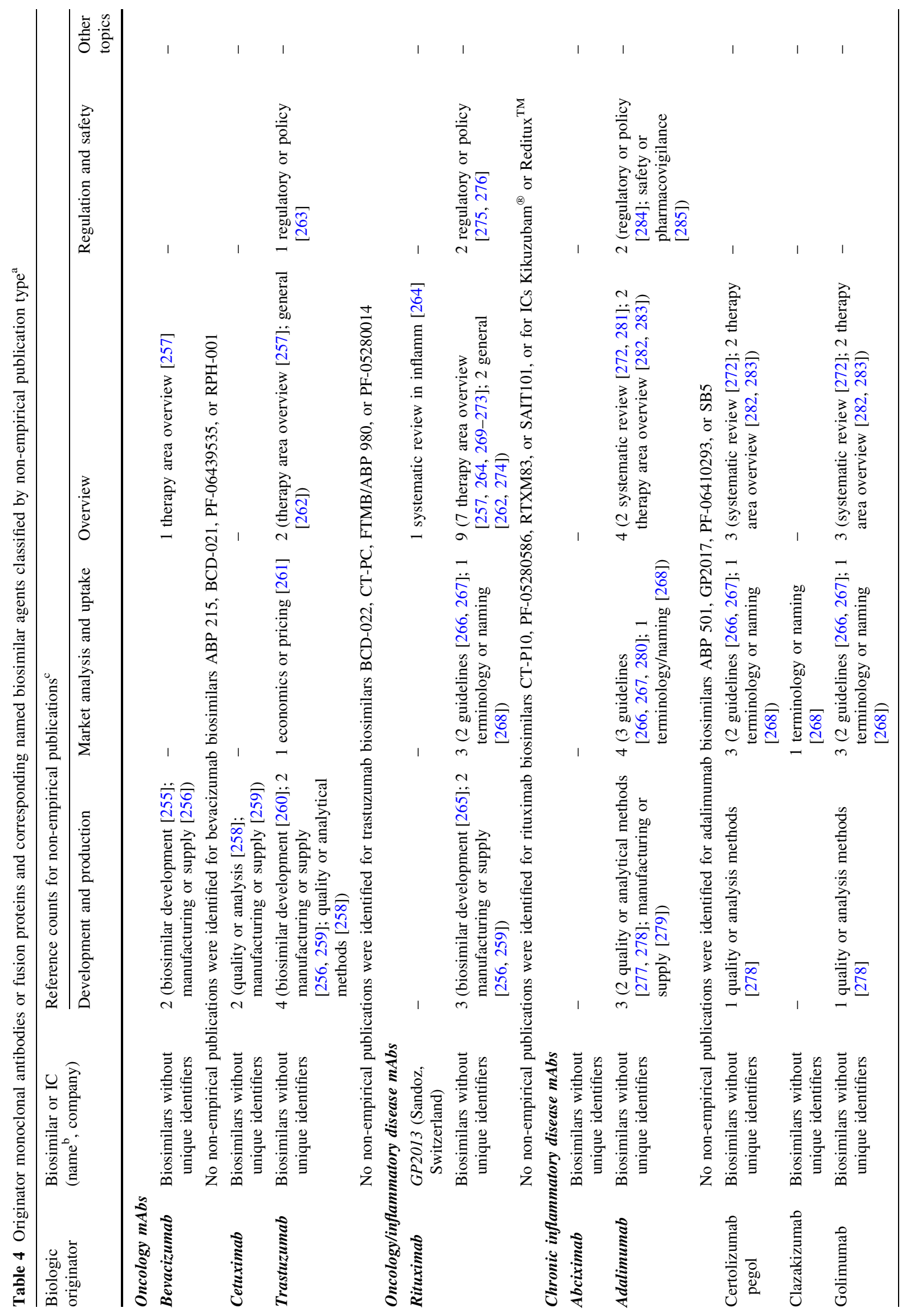




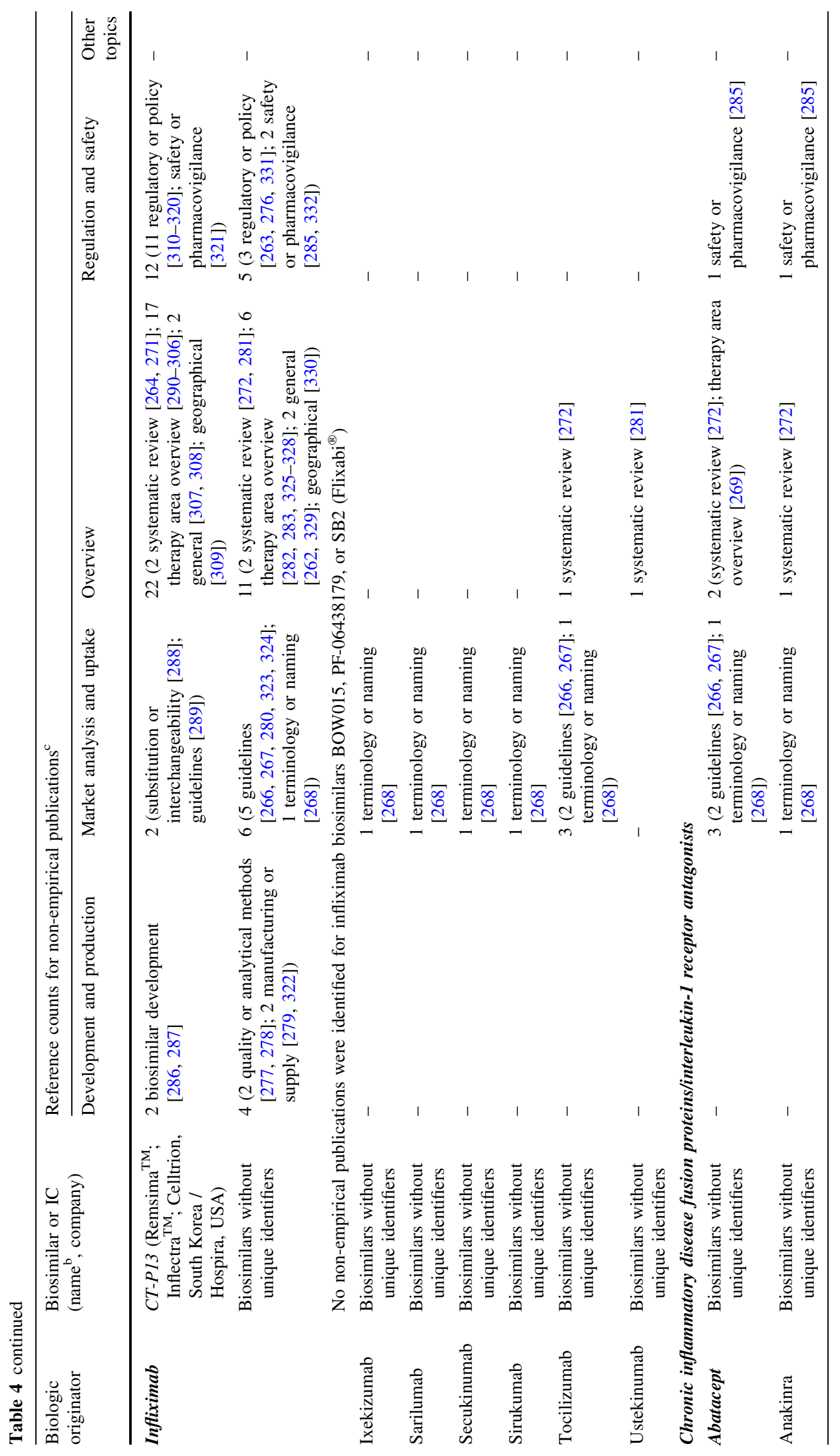




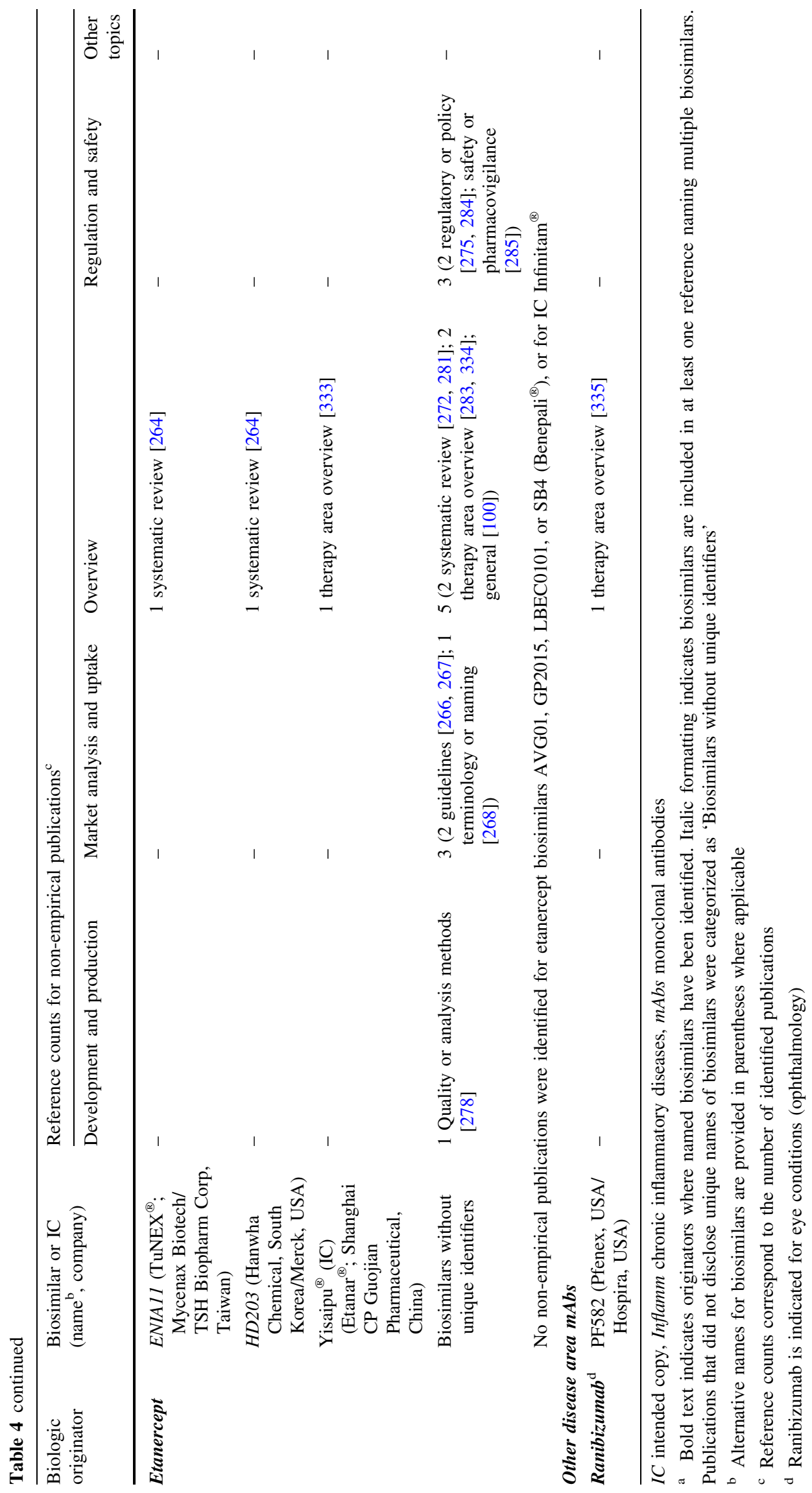


analysis or uptake' were mostly guidelines or reviews on terminology and naming. The majority of non-empirical overview publications were therapy area review articles or systematic literature reviews. Publications on regulation and safety aspects (either regulatory/policy or safety/ pharmacovigilance) were mostly identified for etanercept and infliximab without reference to any named biosimilars. The majority of non-empirical publications naming biosimilars referenced CT-P13, which also appeared most frequently in empirical publications. Other proposed biosimilars featuring in a single non-empirical publication included ENIA11, HD203, PF582, and GP2013.

\subsection{Publishing Trends on Biosimilars}

\subsubsection{Journals}

A total of 110 unique journal publications publishing relevant material on $\mathrm{mAb}$ and fusion protein biosimilars were identified between 2002 and September 2015. The journal $m A b s$ published the most articles on biosimilars, with 19 different articles since 2008, five of which were published in 2015 (ESM Table S4). In September 2011, the journal Biologicals published seven articles in a special issue entitled 'Evaluation of Similar Biotherapeutic products: Scientific and Regulatory Challenges' [91], which focused on the key global health authorities in the evolving regulatory considerations and approval pathways for biosimilars. This issue accounted for nearly half of the sharp rise in publications in a single year, to a total of 19 . The number of publications dropped slightly in $2012(n=15)$, before rising again to 17 and 18 publications in 2013 and 2014, respectively. In 2014, the most articles were published by the journals mAbs $(n=4)$, Annals of Rheumatic Diseases $(n=3)$, Bioanalysis $(n=3)$, and BioDrugs $(n=3)$. Between January and September 2015, nine publications relevant to the topic of $\mathrm{mAb}$ or fusion protein biosimilars were identified, the majority $(n=5)$ in $m A b s$.

\subsubsection{Congresses}

Proceedings from 17 conferences were searched and 192 congress abstracts publishing on biosimilar-relevant topics were identified between 2009 and August 2015.

The top three identified congresses (in order of most abstracts identified between 2009 and August 2015) were European League Against Rheumatism (EULAR) ( $n=48)$, International Society for Pharmacoeconomics and Outcomes Research (ISPOR) $(n=33)$, and American Association of Pharmaceutical Scientists (AAPS) National Biotechnology Conference $(n=24)$ (ESM Table S5). These congresses reflect the diversity of venues at which biosimilars have been presented: disease specific (immunology), outcomes research and payer-focused, and manufacturing. Since 2012, the number of relevant abstract publications has steadily risen from 14 in 2012 to 73 in 2014. In 2015 (up to the analysis cut-off date), 59 abstracts were published on the topic of biosimilars, with the majority (22 abstracts) appearing at the annual EULAR congress and 11 at ECCO.

\section{Discussion}

Although an increasing number and broader range of biosimilars are under development, and recently, the world's first mAb biosimilar was approved under the rigors of the approval process of both the EMA and the FDA, many clinicians still exercise caution over the use of biosimilar products [92, 93]. Findings from the 2015 Coalition of State Rheumatology Organizations (CSRO) survey suggested that, at the time, there were shared concerns over the biosimilar approval process and unaddressed critical issues, including the requirement for clearer guidance from the FDA on interchangeability and naming, which were considered important to address before new biosimilar products arrived onto the market [93]. In a US Alliance for Safe Biologic Medicines (ASBM) survey conducted in 2015 [94, 95], 79\% of physicians considered that a definition of 'biosimilarity' was important/very important for label inclusion. Over $80 \%$ of respondents felt it was important to include analytical and clinical data to demonstrate biosimilarity to the reference product; $79 \%$ regarded the availability of post-marketing data in the biosimilar label as important. As yet, there is no international harmonized approach to the labeling of biosimilars. The FDA has released draft guidance on labeling of biosimilar products [84, 96]. The draft guidance includes the addition of a 'biosimilarity statement' that is intended to describe the biosimilar's relationship with the reference product $[17,96]$. While biosimilar product-specific data are regarded as "necessary to inform safe and effective use of the product," the FDA's stance on inclusion of comparative data in the label is that this may cause confusion among healthcare providers and is not considered particularly "relevant to a health care provider's prescribing considerations" [17]. The draft guidance is currently issued for comment only, and the FDA will seek to incorporate feedback from the public and industry before releasing the finalized guidance. Under EMA guidelines, clinical and preclinical data of the biosimilar are included in the European Public Assessment Report (EPAR), with no requirement to include comparative data on the biosimilar product in the label. Furthermore, there is no citation of the EPAR data in the label. Physicians may, therefore, not be aware of how to access these data and incorrectly assume 
that all information on the biosimilar product is included in the label [97]. Findings from a European survey in seven countries revealed that $90.5 \%$ of physicians use the label frequently or occasionally as an information source and $87.2 \%$ felt that a clear statement on the origin of the data would be helpful [98]. Efficacy and safety considerations notwithstanding, clinicians are becoming increasingly receptive to prescribing biosimilars [99]. Certainly, further clarity around biosimilar labeling will guide clinicians toward making more informed prescribing decisions, which may encourage the effective and appropriate use of these agents in daily clinical practice.

During the course of this research it became evident that a range of umbrella terms for biosimilarity has been adopted to describe different attributes of molecules under development, and in some cases applied to products that have not undergone rigorous similarity exercises, as required by the regulatory bodies (meaning they would be more correctly named 'intended copies', or 'non-comparable biologics') [1, 22, 23]. Thus, the published data available on these products are insufficient to provide robust evidence on their structural/functional similarity and clinical efficacy and safety compared with the originator product [24].

With this in mind, increased efforts should be made to educate healthcare providers and other key stakeholders responsible for the introduction and assimilation of biosimilars into healthcare practice on the major distinction not only between biosimilars of reference biologics and generics of small molecules but also between biosimilars and intended copies or biobetters. As an illustration, across several emerging markets (including Mexico, Columbia, and India), intended copies of biologics are marketed as 'biosimilars' without any published analytical similarity data or robust clinical trials or based on evidence from potentially flawed studies $[1,97,100,101]$. Noteworthy adverse events (grade 3/4) following administration of intended copies of etanercept (Yisaipu ${ }^{\circledR}$ or Infinitam ${ }^{\circledR}$ ) and rituximab $\left(\right.$ Kikuzubam $^{\circledR}$ ) have been reported in Mexico and Columbia [66] along with claims of therapeutic failure [1], which further serves to reinforce the importance of maintaining a clear differentiation between these products and biosimilars approved under the scientific and clinical rigors of similarity assessment, as outlined by regulatory agencies, to ensure the biosimilar drug efficacy and safety are equivalent to those of the originator. Approval of intended copies with limited or non-comparable data may not only jeopardize patient safety but also create potential confusion amongst healthcare stakeholders, especially as these products co-exist on the market with biosimilars while not conforming to the rigorous regulatory standards set by the World Health Organization (WHO) [97] and leading regulatory health agencies such as the EMA and
FDA. A further distinction must be made between biosimilars and 'next-generation biologics' or 'biobetters', which seek to outperform the originator molecules. Since biobetters have been structurally engineered to improve their clinical performance (including improved potency, extended half-life, or reduced adverse events) [1], they are not biosimilars and they must be differentiated on account of structural differences and altered clinical behavior $[1,22,102]$.

Although immunogenicity is a key safety concern for any biologic (i.e., for both originators and biosimilars), the potential for it to arise during biosimilar production as a result of small or undetectable differences between the originator product and the biosimilar [103] presents a unique challenge for biosimilar developers and regulatory agencies. This is of particular importance for $\mathrm{mAb}$ and fusion protein biosimilars because of their large molecular size, complex protein structure, and post-translational modifications [103].

At the time of marketing authorization or approval application, pharmacovigilance and risk-management activities for the post-authorization phase are recommended by the FDA, EMA, and in accordance with the WHO regulations to provide additional data on the safety and efficacy of the biosimilar [104-108]; however, only EMA guidelines specifically address immunogenicity during post-approval surveillance monitoring. Furthermore, as is the case for all medicines, side effects relating to use in daily clinical practice, including off-label use or drug interactions, will only be identified if biosimilar products are continually traced and monitored in post-marketing studies [109, 110]. During the course of our research into biosimilars and intended copies, the majority of clinical studies reported only limited data on immunogenicity versus the originator.

Extrapolation of indications is particularly important for $\mathrm{mAb}$ or fusion protein biosimilar products whose reference agents are licensed for multiple indications [97, 111]. Both the FDA and the EMA permit the extrapolation of biosimilars [97], based on the totality of evidence provided from clinical and nonclinical data, as well as taking into consideration the proposed mechanism of action of the product $[111,112]$. Thus, biosimilar manufacturers need only supply a sufficient degree of evidence to demonstrate biosimilarity, without any requirement to provide clinical trial data for all indications [13, 97, 104]. Indication extrapolation remains an area of uncertainty, with regulatory decisions made on a case-by-case basis, and no 'onesize-fits-all' approach.

As identified in this review, rituximab has a large number of proposed biosimilars under development, both for chronic inflammatory disease and oncology indications. In oncology, biosimilars for trastuzumab, followed by 
bevacizumab, are leading the way; in chronic inflammatory disease, etanercept and infliximab have the most biosimilars as well as the largest volume of published data, particularly for Celltrion's EMA- and FDA-approved biosimilar CT-P13. Almost without exception, studies we reviewed focused on mainly RA (for chronic inflammatory disease), non-squamous non-small-cell lung cancer, non-Hodgkin's lymphoma, and HER2-positive breast cancer (for oncology). At the time of review, no published data for biosimilars in chronic inflammatory diseases were available for psoriasis, psoriatic arthritis, juvenile idiopathic arthritis, Crohn's disease/ulcerative colitis (with the exception of CT-P13), or ankylosing spondylitis (excluding CT-P13). In oncology, among biosimilars of bevacizumab, no published data were available for colorectal cancer, cervical cancer, HER2negative breast cancer, renal cell carcinoma, or recurrent glioblastoma multiforme. Within oncology indications for rituximab biosimilars, no published data were retrieved for chronic lymphocytic leukemia. Development in disease areas outside of oncology and chronic inflammatory disease was less active; only three biosimilars were identified with published data and only two molecules with published empirical data.

Until recently, information comparing biosimilars with their originator product has been limited outside of clinical trials required for biosimilar approval; even less information exists comparing biosimilars of the same reference molecule. In this review, the majority of studies compared biosimilars with their originators. However, due to the widespread use of biologic disease-modifying antirheumatic drug therapy (and availability of intended copies on the market), along with the development and approval of an increasing number of biosimilar agents for chronic inflammatory conditions, research efforts are now turning towards comparisons with products of a different biological class. Assuming all data are made public, this may be of direct benefit to healthcare stakeholders and patients to improve their understanding of how biosimilars compare not only to their reference molecule but also to biologic originators and approved or proposed biosimilars.

The growing number of marketed biosimilar agents available, and increased volume of published clinical data, presents future opportunities to develop post-marketing comparative observational analyses or indirect treatment comparisons, which may also be of benefit to regulatory and healthcare stakeholders to better inform decision making. Despite the existence of a relatively significant amount of analytical, nonclinical, and clinical data, as identified in this study, the majority are published as abstracts in conference proceedings. Further studies published in full text are required to reliably communicate biosimilarity between originators and biosimilars, and the completion of ongoing clinical trials in a variety of biosimilar candidates is expected soon.

This study has provided information on the range of $\mathrm{mAb}$ and fusion protein biosimilars available or in various stages of development and the available scientific data comparing them with their originator. CT-P13 and PF05280014 had the greatest evidence of similarity to their originators on the basis of results from clinical studies involving larger numbers of patients compared with other named biosimilars for which the body of evidence is still growing.

Strong evidence of similarity provided from analytical, PK, and nonclinical studies is as essential as clinical evidence in establishing the safety and efficacy of a biosimilar and in meeting regulatory standards and requirements set by the EMA and FDA for approval [104, 108]. Irrespective of therapy area, this analysis also revealed that a significant number of candidate products had no published evidence (to date) of structural and functional comparability with their originators from preclinical studies. This is true among biosimilars of bevacizumab, trastuzumab, adalimumab, infliximab, rituximab, and etanercept. Not only are these assessments important from a regulatory standpoint for approval, but release of these data in the public domain is also necessary for gaining acceptance among prescribers, payers, and patients and to ensure sustainable market uptake.

Several limitations of the study should be noted. Although the search strategy was designed to capture a relevant set of records, the database searches may not have captured all terms related to therapy area or mAbs or fusion protein biosimilars. Another limitation was that only proceedings from 17 conferences were searched, and although consideration was given to identifying the most likely venues for dissemination of relevant biosimilar research, data may be available from other conference proceedings not considered in this analysis. Owing to a lack of differentiation in the published literature between biosimilars and intended copies or biobetters, molecules may have been labeled as biosimilars without rigorous data to support biosimilarity, which could not be verified from this analysis. Several publications were retrieved with published data on biosimilar molecules and referenced without a distinguishable name. However, only data from publications disclosing names of biosimilars were extracted. The final search result from each database was also limited to reference records published in the English language. The search for ongoing, planned, or complete clinical trials was conducted using the ClinicalTrials.gov results database; no other clinical trial registries were used in this analysis. Therefore, it is possible that some trials (particularly those being conducted outside of the USA) may not have been captured. The registration and dissemination of trial data 
(including updates to protocols) on the ClinicalTrials.gov site is at the full discretion of the study investigator or sponsor and it is possible that some of the captured trial information may be either out of date or inaccurate.

In this analysis, all studies were included regardless of the risk of bias scores. For simplicity, conclusions on biosimilarity were collectively drawn from a variety of clinical study types (e.g., RCTs and observational [prospective or retrospective] studies), without accounting for any variation in the overall quality of evidence provided by each study type. The determination of biosimilarity was based on the specific term(s) chosen by the investigators in formulating their conclusions. Therefore the determination of, for example, 'similar' versus 'highly similar' was based on the scale of reference used by each investigator. Country of origin analyses were also not conducted on the retrieved clinical data. This may present some information bias, owing to varying standards between countries in reporting trial data. In addition, biosimilars may have been evaluated in different patient sub-populations (e.g., DMARD-naïve vs. DMARD-IR [inadequate response] patients); therefore, it may not be possible to draw adequate conclusions on biosimilarity. Note also that when this analysis was conducted, limited data were available for analytical studies, and overall there was an inconsistency in the data reported across studies of the same designated category, limiting the extent to which conclusions could be drawn. The determination of 'proposed biosimilar' versus 'intended copy' is limited in this analysis by uncertainty surrounding the intentions of manufacturers with development candidates. Therefore, the assumption that all development stage molecules are 'proposed biosimilars' may not be accurate. Lastly, as this review represents a cross-sectional analysis of available published evidence over a defined period of time, the authors acknowledge the molecules reviewed are at different stages of development, and thus cannot be compared like-for-like. Since completion of this review, several biosimilars have new published data across study types and several have transitioned into their next stages of development.

Furthermore, new biosimilars in development (which were not captured in this analysis) have since entered the arena. For example, for chronic inflammatory diseases, comparative safety/efficacy trials have since been listed in the ClinicalTrials.gov registry for M923 (adalimumab; Baxalta; psoriasis, RA) and MYL-1401A (adalimumab; Mylan; psoriasis, psoriatic arthritis). In oncology, comparative safety/efficacy trials were recently documented for ABP798 (rituximab; Amgen; non-Hodgkin's lymphoma) and for HLX01 (rituximab; Shanghai Henlius Biotech; CD20 + diffuse large B-cell lymphoma). In other disease areas, a comparative safety/efficacy trial was identified in the update search for FYB201 (ranibizumab; Bioeq $\mathrm{GmbH}$; age-related macular degeneration). It is important therefore, to acknowledge that this systematic review provides only a cross-sectional analysis of biosimilar development activities at the time the analysis was undertaken. The authors may consider performing an update on this systematic review in the future.

\section{Conclusions}

The launch of biosimilars is expected to provide cost savings and offers the potential to expand patient access to important biologic medicines. At the time of writing, two $\mathrm{mAb}$ biosimilars and one fusion protein biosimilar were approved for use in the EU or USA and two further molecules had received recommendations for approval in the USA. However, recent surveys have revealed that some confusion remains surrounding regulatory requirements, labeling, and naming conventions for biosimilars. Additional knowledge gaps also exist for many clinicians and other stakeholders around indication extrapolation.

With this in mind, this systematic review collated and synthesized publically available information from the scientific literature and conference proceedings on biosimilars on the market and in development. The analysis highlighted progress on many fronts to harmonize and clarify regulations and demonstrated the growing evidence base available for biosimilar molecules. While the authors' findings in this regard are reassuring, the analysis also exposed significant differences in the extent of published evidence between molecules at preclinical, clinical, and post-marketing stages of development, something that is particularly true for intended copies.

Concerted efforts by manufacturers and investigators to disseminate available data and address gaps in the literature together with further education and awareness among all key stakeholders will be required to instill confidence and trust in the safety and efficacy of biosimilar medicines, thereby helping to support their use for the benefit of patients.

An update of this SLR in the future may serve to consolidate more recent data and further highlight remaining gaps in the published literature.

Acknowledgements Medical writing support was provided by Robyn Fowler, PhD, of Engage Scientific Solutions, and was funded by Pfizer. Carole Jones of Envision Pharma Group was involved with the development of the SLR, which was funded by Pfizer.

\section{Compliance with Ethical Standards}

Author Contributions All authors were involved in drafting the article and revising it critically for important intellectual content. All authors read and approved the final manuscript submitted for publication. 
Conflict of interest IJ, DP, CKN, CK, and LS are full-time employees and shareholders of Pfizer Inc. GF was a full-time employee of Pfizer Inc. at the time the study was conducted. SL is a full-time employee of Envision Pharma Group who were paid consultants to Pfizer in connection with the development of the SLR report that forms the basis of this manuscript. He was not compensated for his role in the development of this manuscript.

Funding The SLR to support this manuscript was sponsored by Pfizer Inc.

Open Access This article is distributed under the terms of the Creative Commons Attribution-NonCommercial 4.0 International License (http://creativecommons.org/licenses/by-nc/4.0/), which permits any noncommercial use, distribution, and reproduction in any medium, provided you give appropriate credit to the original author(s) and the source, provide a link to the Creative Commons license, and indicate if changes were made.

\section{References}

1. Olech E. Biosimilars: rationale and current regulatory landscape. Semin Arthritis Rheum. 2016;45(5 suppl):S1-10.

2. Tsuruta LR, Lopes dos Santos M, Moro AM. Biosimilars advancements: moving on to the future. Biotechnol Prog. 2015;31(5):1139-49.

3. Sackman J, Kuchenreuther M. The bullish outlook for biosimilars. BioPharm Int 2015;28(2):1-3.

4. Pen A, Klein AV, Wang J. Health Canada's perspective on the clinical development of biosimilars and related scientific and regulatory challenges. GaBI J. 2015;4(1):36-41.

5. IMS Institute for Healthcare Informatics. Delivering on the potential of biosimilar medicines: the role of functioning competitive markets. 2016 March 2016. Available from: http://www. imshealth.com/files/web/IMSH\%20Institute/Healthcare\%20Brie fs/Documents/IMS_Institute_Biosimilar_Brief_March_2016.pdf. Accessed 2016 Jun 21.

6. Dorner T, Strand V, Cornes P, Goncalves J, Gulacsi L, Kay J, et al. The changing landscape of biosimilars in rheumatology. Ann Rheum Dis. 2016;74(6):974-82.

7. Krishnan A, Mody R, Malhotra H. Global regulatory landscape of biosimilars: emerging and established market perspectives. Biosimilars. 2015;5:19-32.

8. Generics and Biosimilars Initiative (GaBi). Biosimilars applications under review by EMA - December 2015. 29 Jan 2016. Available from: http://www.gabionline.net/Biosimilars/General/ Biosimilars-applications-under-review-by-EMA-December-2015. Accessed 2016 Jun 22

9. European Medicines Agency. European Medicines Agency recommends approval of first two monoclonal-antibody biosimilars [press release]. 25 Jun 2013. Available from: http:// www.ema.europa.eu/ema/index.jsp?curl=pages/news_and_events/ news/2013/06/news_detail_001837.jsp\&mid=WC0b01ac05800 $4 \mathrm{~d} 5 \mathrm{c} 1$. Accessed 2016 Jun 21.

10. Samsung Bioepis. Samsung Bioepis becomes first to obtain European Commission Approval for second anti-TNF- $\alpha$ biosimilar with Flixabi ${ }^{\circledR} .30$ May 2016. Available from: http:// www.businesswire.com/news/home/20160529005047/en/. Accessed 2016 Jun 21.

11. Samsung Bioepis. BENEPALI ${ }^{\circledR}$, the first etanercept iosimilar referencing Enbrel $^{\circledR}$, approved in the European Union [news report]. 16 Jan 2016. Available from: http://www.businesswire. com/news/home/20160116005011/en/BENEPALI\%C2\%AE-
Etanercept-Biosimilar-Referencing-Enbre1\%C2\%AE-ApprovedEuropean. Accessed 2016 Jun 21.

12. Amgen. Amgen's first biosimilar marketing authorization application submitted to European Medicines Agency for ABP 501 [news release] 4 Dec 2015. Available from: http://www. prnewswire.com/news-releases/amgens-first-biosimilar-market ing-authorization-application-submitted-to-european-medicinesagency-for-abp-501-300187922.html. Accessed 2016 Jun 21.

13. Samsung Bioepis. Samsung Bioepis submits marketing authorization application for SB2, A Remicade (infliximab) biosimilar candidate, to the European Medicines Agency [news release]. 13 May 2015. Available from: http://www.prnewswire.com/newsreleases/samsung-bioepis-submits-marketing-authorizationapplication-for-sb2-a-remicade-infliximab-biosimilar-candidateto-the-european-medicines-agency-300048841.html. Accessed 2016 Jun 21.

14. European Medicines Agency. EMA accepts application for etanercept biosimilar [news release]. 15 Jan 2016. Available from: http://www.gabionline.net/Biosimilars/News/EMA-accepts-app lication-for-etanercept-biosimilar. Accessed 2016 Jun 21.

15. Gaffney A. After three-year delay, FDA finalizes guidance documents on biosimilarity. 28 April 2015. Available from: http://www.raps.org/Regulatory-Focus/News/2015/04/28/22058/ After-Three-Year-Delay-FDA-Finalizes-Guidance-Documentson-Biosimilarity/. Accessed 2016 Jun 21.

16. US Food and Drug Administration. FDA releases draft guidance for industry: "Labeling for biosimilar products". 1 Apr 2016. Available from: http://www.pharmoutsourcing.com/1315-News/ 184872-FDA-Releases-Draft-Guidance-for-Industry-Labelingfor-Biosimilar-Products/?catid=6261. Accessed 2016 Jun 21.

17. Christl L. From our perspective: biosimilar product labeling. 15 June 2016. Available from: http://www.fda.gov/Drugs/News Events/ucm493240.htm? source=govdelivery\&utm_medium= email\&utm_source=govdelivery. Accessed 2016 Jun 21.

18. US Food and Drug Administration. FDA approves Inflectra, a biosimilar to Remicade [news release]. 5 Apr 2016. Available from: http://www.fda.gov/NewsEvents/Newsroom/PressAnnoun cements/ucm494227.htm. Accessed 2016 Jun 21.

19. US Food and Drug Administration. FDA Arthritis Advisory Committee recommends CTP 13 (infliximab biosimilar) for all indications of the reference product - Hospira/Pfizer [news release]. $11 \mathrm{Feb}$ 2016. Available from: http://www.epgonline. org/news/fda-arthritis-advisory-committee-recommends-ctp-13infliximab-biosimilar.cfm. Accessed 2016 Jun 21.

20. Novartis. FDA accepts Sandoz regulatory submission for a proposed biosimilar etanercept. 2016. Available from: https:// www.novartis.com/news/media-releases/fda-accepts-sandozregulatory-submission-proposed-biosimilar-etanercept. Accessed 2016 Jun 19

21. Barber J. FDA advisory panel backs Amgen's proposed biosimilar of AbbVie's Humira. 12 July 2016. Available from: http://www.firstwordpharma.com/node/1399106\#axzz4EO2ytw 2T. Accessed 2016 Jul 19.

22. Weise M, Bielsky MC, De Smet K, Ehmann F, Ekman N, Narayanan G, et al. Biosimilars-why terminology matters. Nat Biotechnol. 2011;29(8):690-3.

23. Wadhwa M, Thorpe M. Terminology for biosimilars-a confusing minefield. GaBI J. 2012;1(3-4):132-4.

24. Mysler E, Pineda C, Horiuchi T, Singh E, Mahgoub E, Coindreau J, et al. Clinical and regulatory perspectives on biosimilar therapies and intended copies of biologics in rheumatology. Rheumatol Int. 2016;36(5):613-25.

25. Moher D, Liberati A, Tetzlaff J, Altman DG. Preferred reporting items for systematic reviews and meta-analyses: the PRISMA statement. J Clin Epidemiol. 2009;62(10):1006-12. 
26. Liberati A, Altman DG, Tetzlaff J, Mulrow C, Gotzsche PC, Ioannidis JP, et al. The PRISMA statement for reporting systematic reviews and meta-analyses of studies that evaluate health care interventions: explanation and elaboration. J Clin Epidemiol. 2009;62(10):e1-34.

27. National Institute for Health Care Excellence. Single technology appraisal: user guide for company evidence submission template. Jan 2015. Available from: http://www.nice.org.uk/article/ pmg24. Accessed 2016 Jun 21.

28. Jadad AR, Moore RA, Carroll D, Jenkinson C, Reynolds DJ, Gavaghan DJ, et al. Assessing the quality of reports of randomized clinical trials: is blinding necessary? Control Clin Trials. 1996;17(1):1-12.

29. Downs SH, Black N. The feasibility of creating a checklist for the assessment of the methodological quality both of randomised and non-randomised studies of health care interventions. J Epidemiol Community Health. 1998;52(6):377-84.

30. Hooijmans CR, Rovers MM, de Vries RB, Leenaars M, RitskesHoitinga M, Langendam MW. SYRCLE's risk of bias tool for animal studies. BMC Med Res Methodol. 2014;14:43.

31. Drummond MF, Jefferson TO. Guidelines for authors and peer reviewers of economic submissions to the BMJ. The BMJ Economic Evaluation Working Party. BMJ. 1996;313(7052):275-83.

32. Moher D, Liberati A, Tetzlaff J, Altman DG. Preferred reporting items for systematic reviews and meta-analyses: the PRISMA statement. BMJ. 2009;339:b2535.

33. Shamseer L, Moher D, Clarke M, Ghersi D, Liberati A, Petticrew M, et al. Preferred reporting items for systematic review and meta-analysis protocols (PRISMA-P) 2015: elaboration and explanation. BMJ. 2015;349:g7647.

34. Wisman LAB, De Cock EPM, Reijers JAA, Kamerling IMC, Van Os SHG, de Kam ML, et al. A phase I dose-escalation and bioequivalence study of a trastuzumab biosimilar in healthy male volunteers. Clin Drug Investig. 2014;34(12):887-94.

35. Yin D, Barker KB, Li R, Meng X, Reich SD, Ricart AD, et al. A randomized phase 1 pharmacokinetic trial comparing the potential biosimilar PF-05280014 with trastuzumab in healthy volunteers (REFLECTIONS B327-01). Br J Clin Pharmacol. 2014;78(6):1281-90.

36. Roy PS, John S, Karankal S, Kannan S, Pawaskar P, Gawande J, et al. Comparison of the efficacy and safety of Rituximab $\left(\right.$ Mabthera $^{\mathrm{TM}}$ ) and its biosimilar (Reditux ${ }^{\mathrm{TM}}$ ) in diffuse large B-cell lymphoma patients treated with chemo-immunotherapy: a retrospective analysis. Indian $\mathbf{J}$ Med Paediatr Oncol. 2013;34(4):292.

37. Thakral P, Singla S, Yadav MP, Vasisht A, Sharma A, Gupta SK, et al. An approach for conjugation of 177Lu-DOTA-SCNrituximab (BioSim) \& its evaluation for radioimmunotherapy of relapsed \& refractory B-cell non Hodgkins lymphoma patients. Indian J Med Res. 2014;139(4):544.

38. Alexeev S, Zaritskey A, Volodicheva E, Loginov A, Orlova R, Dvornichenko V, et al. Clinical comparability of BCD-020 to innovator rituximab in patients with indolent non-Hodgkin's lymphoma. Haematologica. 2014;99:144-5.

39. Aliaga L, Fernandez I, Sanchez M, Saavedra H, Espinoza C. Pharmacovigilance of anti CD 20 monoclonal antibody biosimilar at the Edgardo Rebagliati Martins Hospital-Peru. Drug Saf. 2013;36:925.

40. Filon O, Orlov SV, Burdaeva ON, Kopp MIV, Kotiv BN, Alekseev S, et al. Efficacy and safety of BCD-021, bevacizumab biosimilar candidate, compared to Avastin: results of international multicenter randomized double blind phase III study in patients with advanced non-squamous NSCLC [abstract 8057]. 2015 American Society of Clinical Oncology (ASCO) Annual Meeting; 201529 May-2 June 2015; Chicago, IL: J Clin Oncol. 2015;33(suppl; abstr 8057). http://meetinglibrary.asco.org/ content/152128-156.

41. Florez A, Di Matteo T, Fresnillo G, Tudela C, Seigelchifer M, Corley E, et al. Clinical pharmacokinetic (PK) and safety (immunogenicity) of rituximab biosimilar RTXM83 in combination with chemotherapy CHOP in patients with diffuse large B-cell lymphoma (DLBCL). Blood. 2014;124(21):5472.

42. Im Y, Krasnozhon D, Bondarenko I, Zvirbule Z, Jung K, Oliynychenko P, et al. Phase I/IIb clinical trial comparing PK and safety of trastuzumab and its biosimilar candidate CT-P6 [abstract S108]. 2013. S108-S]. Available from: http://www. biosimilarz.com/wp-content/uploads/2013/03/ct-p06-in-mbc abstract_st-gallen-2013_13mar2013.pdf. Accessed 2016 Jun 22.

43. Im Y, Odarchenko P, Grecea D, Komov D, Anatoliy CV, Gupta $\mathrm{S}$, et al. Double-blind, randomized, parallel group, phase III study to demonstrate equivalent efficacy and comparable safety of CT-P6 and trastuzumab, both in combination with paclitaxel, in patients with metastatic breast cancer (MBC) as first-line treatment. J Clin Oncol. 2013;31:629.

44. Kim SJ, Kim WS, Kang HJ, Kim JS, Choi CW, Lee SI, et al. Safety, pharmacokinetic/pharmacodynamic profiles and efficacy of sait101, a biosimilar of rituximab in patients with diffuse large b-cell lymphoma. Haematologica. 2012;97 S317-S8.

45. Markus R, Kaur PP, Chow V, Zhang N, Born TL, Huynh Q, et al. Results of functional testing and pharmacokinetics comparing ABP 215 to bevacizumab [abstract no. 711]. J Clin Oncol. 2015;33.

46. Menon H, Yadav A, Subramanian PG, Sengar M, Rath S, Kavathiya K, et al. Pharmacokinetic and pharmacodynamic properties of a biosimilar rituximab (Reditux ${ }^{(\mathbb{B}}$ ) are identical to the innovator brand MabThera ${ }^{\circledR}$ - experience from a tertiary cancer centre in Western India. Blood. 2014;124(21):2246.

47. Orlov SV, Burdaeva ON, Nachaeva MP, Kopp MV, Kotiv BN, Sheveleva LP, et al. Pharmacokinetics and safety of BCD-021, bevacizumab biosimilar candidate, compared to Amastin in patients [abstract no. e13500]. J Clin Oncol. 2014;32.

48. Stenina MB, Ignatova E, Frolova MA, Burdaeva ON, Nechaeva MP, Kopp MV, et al. Pharmacokinetics and safety of BCD-022, trastuzumab biosimilar candidate, compared to Herceptin in patients [abstract e11576]. J Clin Oncol. 2014;32 Suppl.

49. da Silva A, Kronthaler U, Koppenburg V, Fink M, Meyer I, Papandrikopoulou A, et al. Target-directed development and preclinical characterization of the proposed biosimilar rituximab GP2013. Leuk Lymphoma. 2014;55(7):1609-17.

50. Hurst S, Ryan AM, Ng C-K, McNally JM, Lorello LG, Finch GL, et al. Comparative nonclinical assessments of the proposed biosimilar PF-05280014 and Trastuzumab (Herceptin $\left.{ }^{\circledR}\right)$. BioDrugs. 2014;28(5):451-9.

51. Ryan AM, Sokolowski SA, Ng C-K, Shirai N, Collinge M, Shen $\mathrm{AC}$, et al. Comparative nonclinical assessments of the proposed biosimilar PF-05280586 and rituximab (MabThera ${ }^{\circledR}$ ). Toxicol Pathol. 2014;42(7):1069-81.

52. Choe J-Y, Prodanovic N, Niebrzydowski J, Staykov I, Dokoupilova E, Baranauskaite A, et al. A randomised, double-blind, phase III study comparing SB2, an infliximab biosimilar, to the infliximab reference product Remicade in patients with moderate to severe rheumatoid arthritis despite methotrexate therapy. Ann Rheum Dis. doi:10.1136/annrheumdis-2015-207764.

53. Emery P, Vencovský J, Sylwestrzak A, Leszczyński P, Porawska W, Baranauskaite A, et al. A phase III randomised, double-blind, parallel-group study comparing SB4 with etanercept reference product in patients with active rheumatoid arthritis despite methotrexate therapy. Ann Rheum Dis. doi:10. 1136/annrheumdis-2015-207588.

54. Gu NY, Yi SJ, Kim T-E, Kim JW, Shin S-G, Jang I-J, et al. Comparative pharmacokinetics and tolerability of branded 
etanercept $(25 \mathrm{mg})$ and its biosimilar $(25 \mathrm{mg})$ : a randomized, open-label, single-dose, two-sequence, crossover study in healthy Korean male volunteers. Clin Ther. 2011;33(12):2029-37.

55. Jani RH, Gupta RV, Bhatia G, Rathi G, P. AK, Sharma R, et al. A prospective, randomized, double-blind, multicentre, parallelgroup, active controlled study to compare efficacy and safety of biosimilar adalimumab (Exemptia; ZRC-3197) and adalimumab (Humira) in patients with rheumatoid arthritis. Int J Rheum Dis (Epub 14 Jul 2015).

56. Park W, Jaworski J, Brzezicki J, Gnylorybov A, Kadinov V, Goecke Sariego I, et al. A randomised, double-blind, parallelgroup, phase 1 study comparing the pharmacokinetics, safety and efficacy of CT-P13 and infliximab in patients with active ankylosing spondylitis: 54 week results from the PLANETAS study. Ann Rheum Dis. 2013;72:A516-7.

57. Yi SJ, Kim SE, Park M-K, Yoon SH, Cho J-Y, Lim KS, et al. Comparative pharmacokinetics of HD203, a biosimilar of etanercept, with marketed etanercept $\left(\right.$ Enbrel $\left.^{\circledR}\right)$. BioDrugs. 2012;26(3):177-84.

58. Yoo DH, Hrycaj P, Miranda P, Ramiterre E, Piotrowski M, Shevchuk S, et al. A randomised, double-blind, parallel-group study to demonstrate equivalence in efficacy and safety of CTP13 compared with innovator infliximab when coadministered with methotrexate in patients with active rheumatoid arthritis: the PLANETRA study. Ann Rheum Dis. 2013;72(10):1613-20.

59. Farkas K, Rutka M, Bálint A, Nagy F, Bor R, Milassin Á, et al. Efficacy of the new infliximab biosimilar CT-P13 induction therapy in Crohn's disease and ulcerative colitis-experiences from a single center. Expert Opin Biol Ther. 2015;15(9):1257-62.

60. Jung YS, Park DI, Kim YH, Lee JH, Seo PJ, Cheon JH, et al. Efficacy and safety of CT-P13, a biosimilar of infliximab, in patients with inflammatory bowel disease: a retrospective multicenter study. J Gastroenterol Hepatol. 2015;30(12):1705-12.

61. Kang Y-S, Moon HH, Lee SE, Lim YJ, Kang HW. Clinical experience of the use of CT-P13, a biosimilar to infliximab in patients with inflammatory bowel disease: a case series. Dig Dis Sci. 2015;60(4):951-6.

62. Roshique KK, Ravindran V. Efficacy and safety of a biosimilar rituximab in biologic naive patients with active rheumatoid arthritis. Clin Rheumatol. 2015;34(7):1289-92.

63. Vencovský J, Sylwestrzak A, Leszczyński P, Porawska W, Baranauskaite A, Tseluyko V, et al. A Phase III randomised, double-blind clinical study comparing SB4, an etanercept biosimilar, with etanercept reference product $\left(\right.$ Enbrel $\left.^{\circledR}\right)$ in patients with moderate to severe rheumatoid arthritis despite methotrexate therapy (24-week results). Ann Rheum Dis. 2015;74:467-8.

64. Bae S-C, Kim J, Choe J-Y, Park W, Lee SR, Ahn Y, et al. A randomized, double-blind, Phase 3 equivalence trial comparing the etanercept biosimilar, HD203, with etanercept (Enbrel (R)), in combination with methotrexate (MTX) in patients with rheumatoid arthritis (RA). Ann Rheum Dis. 2014;73:63-4. doi:10.1136/annrheumdis-2014-eular.3558.

65. Bandyopadhyay S. Safety and efficacy of rituximab-biosimilar for the treatment of moderate to severe rheumatoid arthritis patients following the failure of disease-modifying drugs: a case series from Apollo Gleneagles Hospital, Kolkata. Indian Rheumatology Association 29th Annual Conference (IRACON 2013); 2013 6-8 December 2013; Kolkota, Calcutta, India; 2013, pp. S4-5.

66. Barile-Fabris LA, Irazoque-Palazuelos F, Hernandez Vasquez R, Carrillo Vazquez S, Guzman R. Incidence of adverse events in patients treated with intended copies of biologic therapeutic agents in Colombia and Mexico. Arthritis Rheum. 2014;66:S662. doi:10.1007/s10067-014-2841-6.
67. Becker J-CP, Yin D, Melia LA, Li R, Gumbiner B, Thomas D, et al. A Phase I trial comparing PF-05280586 (a potential biosimilar) and rituximab in subjects with active rheumatoid arthritis. Arthritis Rheum. 2014;66:S660-S1.

68. Codreanu C, Mogosan C, Enache L, Stanciu D, Ionescu R, Opris D, et al. Romanian Registry of rheumatic diseases: efficacy and safety of biologic therapy in rheumatoid arthritis. Ann Rheum Dis. 2015;74:458.

69. Chung H, Ahn L, Choi Y, Shin S, Jang I, Yu K, et al. LBEC0101, an etanercept biosimilar, showed comparable tolerability and pharmacokinetic profiles to those of etanercept in healthy male volunteers. Clin Pharmacol Ther. 2014;95:S38. doi:10.1038/clpt.2013.247.

70. Gecse K, Farkas K, Lovász B, Banai J, Bene L, Gasztonyi B, et al. Biosimilar Infliximab in inflammatory bowel diseases: first interim results from a prospective nationwide observational cohort. Z Gastroenterol. 2015;53(05):A11.

71. Kaur P, Chow V, Zhang N, Moxness M, Markus R. A randomized, single-blind, single-dose, three-arm, parallel group study in healthy subjects to demonstrate pharmacokinetic equivalence of ABP 501 and adalimumab: Results of comparison with adalimumab (EU). Ann Rheum Dis. 2014;73:479.

72. Kay J, Chopra A, Chandrashekara S, Olakkengil DJ, Bhojani KS, Bhatia G, et al. A phase 3, randomized, double-blind, active comparator study of the efficacy and safety of BOW015, a biosimilar infliximab, in patients with active rheumatoid arthritis on stable methotrexate doses. Ann Rheum Dis. 2014;73:64.

73. Kierkus J. Preliminary assessment of efficacy and safety of switching between originator and biosimilar infliximab in paediatric Crohn disease patients. Gastroenterology. 2015;148(4 Suppl 1):S782-3.

74. Lee YJ, Shin D, Kim Y, Kang JW, Fuhr R, Gauliard A. SAT0176 a phase I pharmacokinetic study comparing SB4, an etanercept biosimilar, and etanercept reference product (Enbrel $^{\circledR}$ ) in healthy male subjects. Ann Rheum Dis. 2015;74(Suppl 2):718. doi:10.1136/annrheumdis-2015-eular.2671.

75. Moctezuma JF, Martinez A, Enkerlin H, Garcia C, Chavez B, Salazar-Teran N, et al. Comparative, randomized, simple blind to evaluate efficacy and safety of infinitam ${ }^{\circledR}$ (etanercept), associated with methotrexate compared with Enbrel ${ }^{\circledR}$ (etanercept) associated with methotrexate in patients with modeate and severe rheumatoid arthritis. Ann Rheum Dis. 2013;72:A234-A.

76. Molnar T, Farkas K, Rutka M, Balint A, Nagy F, Bor R, et al. Efficacy of the new infliximab biomarker CT-P13 induction therapy on mucosal healing in ulcerative colitis patients. J Crohns Colitis. 2015;9 Suppl 1:S382. doi:10.1093/ecco-jcc/ jju027.721.

77. Murphy C, Sugrue K, Mohamad G, McCarthy J, Buckley M. Biosimilar but not the same. J Crohns Colitis. 2015;9(Suppl 1):S331-2.

78. Shin D, Kim YH, Kim YS, Fuhr R, Körnicke T. A Phase I pharmacokinetic study comparing SB2, an infliximab biosimilar, and infliximab reference product (Remicade ${ }^{\circledR}$ ) in healthy subjects. Ann Rheum Dis. 2015;74:703.

79. Santos-Moreno P, Saavedra-Martinez G, Villarreal L, Gomez D, Bello-Gualtero J, Giraldo V, et al. Etanar-A etanercept biosimilar is as effective as adalimumab and infliximab in a cohort of real-life of patients with rheumatoid arthritis. Ann Rheum Dis. 2015;74:789-90.

80. Shin D, Kim YH, Kim HS, Fuhr R, Körnicke T. A Phase I pharmacokinetic study comparing SB5, an adalimumab biosimilar, and adalimumab reference product (Humira ${ }^{\circledR}$ ) in healthy subjects. Ann Rheum Dis. 2015;74:459-60.

81. Udata C, Hua SY, Yin D, Salts S, Meng X, Rehman MI. A Phase I pharmacokinetics trial comparing PF-06438179 (a potential 
biosimilar) and infliximab in healthy volunteers (REFLEXTIONS B537-01). Ann Rheum Dis. 2014;73:494.

82. Yoo DH, Park W, Shim S-C, Suh C-H, Yun J, Pyo T. A randomized, double-blind, three-arm, parallel group, single-dose study to compare the pharmacokinetics, safety, and tolerability of three formulations of infliximab (CT-P13, EU-sourced infliximab and US-sourced infliximab) in healthy volunteers. Arthritis Rheum. 2014;66(Suppl):1509.

83. Yoo DH, Park W, Jeka S, Cons Molina F, Hrycaj P, Wiland P, et al. Impact of anti-drug antibody on efficacy and safety over week 24 in both CT-P10 and innovator rituximab treatment groups. Arthritis Rheum. 2014;65(Suppl 10):S736.

84. Maity S, Ullanat R, Lahiri S, Shekar S, Sodhan G, Vyas A, et al. A non-innovator version of etanercept for treatment of arthritis. Biologicals. 2011;39(6):384-95.

85. Brodszky V, Baji P, Balogh O, Péntek M. Budget impact analysis of biosimilar infliximab (CT-P13) for the treatment of rheumatoid arthritis in six Central and Eastern European countries. Eur J Health Econ. 2014;15(1):65-71.

86. Jha A, Upton A, Dunlop WCN, Akehurst R. The budget impact of biosimilar infliximab (Remsima ${ }^{\circledR}$ ) for the treatment of autoimmune diseases in five European countries. Adv Ther. 2015;32(8):742-56

87. Wu B, Song Y, Leng L, Bucala R, Lu LJ. Treatment of moderate rheumatoid arthritis with different strategies in a health resource-limited setting: a cost-effectiveness analysis in the era of biosimilars. Clin Exp Rheumatol. 2015;33(1):20-6.

88. Choi DH, Suh JW, Park KW, Kang HJ, Kim HS. Assessment of the bioequivalence of brand and biogeneric formulations of abciximab for the treatment of acute coronary syndrome: a prospective, open-label, randomized, controlled study in Korean patients. Clin Ther. 2009;31(8):1804-11.

89. Zhou B, Lin B, Li J, Qian W, Hou S, Zhang D, et al. Tolerability, pharmacokinetics and pharmacodynamics of CMAB007, a humanized anti-immunoglobulin $\mathrm{E}$ monoclonal antibody, in healthy Chinese subjects. MAbs. 2012;4(1):110-9.

90. Flores-Ortiz LF, Campos-García VR, Perdomo-Abúndez FC, Pérez NO, Medina-Rivero E. Physicochemical properties of rituximab. J Liq Chromatogr Relat Technol. 2014;37(10):1438-52.

91. Griffiths E, Thorpe R, Wadhwa M, Yeowon S. Evaluation of similar biotherapeutic products: scientific and regulatory challenges. Biologicals. 2011;39(5):249-358.

92. North American Center for Continuing Medical Education. CME survey: biosimilars. 24 May 2013. Available from: http:// www.naccme.com/sites/naccme.com/files/biosimilar-surveyresults.pdf. Accessed 2016 Jun 21.

93. Coalition of State Rheumatology Organizations (CSRO). CSRO releases Physician Biosimilars Survey results [press release]. 26 May 2016; Available from: http://csro.info/app/document/ 8382846;jsessionid=P5zJOo6TwPYoXVXzwSYawvyM. undefined. Accessed 2016 Jun 21.

94. Alliance for Safe Biologic Medicines (ASBM). New ASBM survey provides physicians' views on biosimilar labeling [news release]. Feb 2015; Available from: https://safebiologics.org/ 2015/03/new-asbm-survey-provides-physicians-views-on-biosi milar-labeling/. Accessed 2016 Jun 21.

95. Olson K. ASBM labeling survey. Feb 2015; Available from: http://docs.house.gov/meetings/IF/IF14/20160204/104408/HHR G-114-IF14-20160204-SD010.pdf. Accessed 2016 Jun 22.

96. US Food and Drug Administration. Labeling for biosimilar products: guidance for industry, draft guidance. March 2016. Available from: http://www.fda.gov/downloads/Drugs/ GuidanceComplianceRegulatoryInformation/Guidances/UCM4 93439.pdf. Accessed 2016 Jun 21.
97. Macdonald JC, Hartman H, Jacobs IA. Regulatory considerations in oncologic biosimilar drug development. MAbs. 2015;7(4):653-61.

98. Hallersten A, Furst W, Mezzasalma R. Physicians prefer greater detail in the biosimilar label (SmPC). Results of a survey across seven European countries. Regul Toxicol Pharmacol. 2016;77:275-81.

99. Market Wired. Nearly half of US physicians say they will prescribe more biosimilars, according to new data from InCrowd [news release]. 3 March 2016. Available from: http://www. marketwired.com/press-release/nearly-half-us-physicians-saythey-will-prescribe-more-biosimilars-according-new-data-2102 567.htm. Accessed 2016 Jun 21.

100. Azevedo VF, Galli N, Kleinfelder A, D'Ippolito J, Urbano PC. Etanercept biosimilars. Rheumatol Int. 2015;35(2):197-209.

101. Azevedo VF, Sandorff E, Siemak B, Halbert RJ. Potential regulatory and commercial environment for biosimilars in Latin America. Value Health Reg Issues. 2012;1:228-34.

102. Pitts P, Stark R. Biosimilars: the precarious struggle between cost-driven health care policy and patient-centered care. 27 Sep 2012. Available from: http://www.washingtonpolicy.org/ publications/detail/biosimilars-the-precarious-struggle-betweencost-driven-health-care-policy-and-patient-centered-care. Accessed 2016 Jun 23.

103. Mellstedt $\mathrm{H}$. Clinical considerations for biosimilar antibodies. EJC Suppl. 2013;11(3):1-11.

104. European Medicines Agency. Guideline on similar biological medicinal products containing biotechnology-derived proteins as active substance: non-clinical and clinical issues. 1 July 2015. Available from: http://www.ema.europa.eu/docs/en_GB/ document_library/Scientific_guideline/2015/01/WC500180219. pdf. Accessed 2016 Jun 21.

105. WHO Expert Committee on Biological Standards. Guidelines on evaluation of similar biotherapeutic products (SBPs). 19-23 Oct 2009. Available from: http://www.who.int/biologicals/areas/ biological_therapeutics/BIOTHERAPEUTICS_FOR_WEB_22 APRIL2010.pdf. Accessed 2016 Jun 21.

106. World Health Organization. Guidelines on the quality, safety, and efficacy of biotherapeutic protein products prepared by recombinant DNA technology. 21-25 Oct 2013. Available from: http://www.who.int/biologicals/biotherapeutics/rDNA_DB_ final_19_Nov_2013.pdf. Accessed 2016 Jun 21.

107. US Food and Drug Administration. Immunogenicity assessment for therapeutic protein products: guidance for industry. Aug 2014. Available from: http://www.fda.gov/downloads/drugs/ guidancecomplianceregulatoryinformation/guidances/ucm3388 56.pdf. Accessed 2016 Jun 21.

108. US Food and Drug Administration. Scientific considerations in demonstrating biosimilarity to a reference product. Guidance for industry. April 2015. Available from: http://www.fda.gov/ downloads/drugs/guidancecomplianceregulatoryinformation/ guidances/ucm291128.pdf. Accessed 2016 Jun 21.

109. Zuniga L, Calvo B. Biosimilars: pharmacovigilance and risk management. Pharmacoepidemiol Drug Saf. 2010;19(7):661-9.

110. Blank T. Safety and toxicity of biosimilars-EU versus US regulation. GaBI J. 2013;2(3):144-50.

111. Zelenetz AD, Ahmed I, Braud EL, Cross JD, Davenport-Ennis N, Dickinson BD, et al. NCCN Biosimilars White Paper: regulatory, scientific, and patient safety perspectives. J Natl Compr Canc Netw. 2011;9(Suppl 4):S1-22.

112. Schneider CK, Vleminckx C, Gravanis I, Ehmann F, Trouvin $\mathrm{JH}$, Weise M, et al. Setting the stage for biosimilar monoclonal antibodies. Nat Biotechnol. 2012;30(12):1179-85.

113. Dorvignit D, Palacios JL, Merino M, Hernandez T, Sosa K, Casaco A, et al. Expression and biological characterization of an 
anti-CD20 biosimilar candidate antibody: a case study. MAbs. 2012;4(4):488-96.

114. Kaplanov K, Zaritskiy A, Alexeev S, Volodicheva E, Loginov A, Orlova R, et al. Key results of international randomized openlabel clinical study of BCD-020 (rituximab biosimilar candidate) in patients with B-cell non-Hodgkin's lymphoma. Blood. 2014;124(21):5467. http://www.bloodjournal.org/content/124/ 21/5467? sso-checked=true.

115. Poddubnaya I, Babicheva L, Kaplanov K, Zaritskey A, Volodicheva $\mathrm{E}$, Alexeev S, et al. Comparison of pharmacokinetics and pharmarodynamics of BCD-020 with innovator rituximab to palients with indolent non-Hodgkin lymphoma. J Clin Oncol. 2014;32(15):e19545.

116. Yoo DH, Park W, Jeka S, Molina FC, Hrycaj P, Wiland P, et al. A randomized, controlled, multicenter, 2-arm, parallel-group, double-blind study to demonstrate the equivalence of CT-P10 to innovator rituximab with respect to pharmacokinetic profile in patients with rheumatoid arthritis. Arthritis Rheum. 2013;65(Suppl 10):1736.

117. da Silva A, Kronthaler U, Meyer I, Papandrikopoulou A, Stangler T, Visser JM. Target-directed development of a proposed biosimilar rituximab (GP2013): comparability of antibody-dependent cellular cytotoxicity activity and PRE-clinical pharmacokinetics and pharmacodynamics with originator rituximab. American College of Rheumatology/Association of Rheumatology Health Professionals Annual Scientific Meeting; 9-14 November 2012; Washington DC; 2012: S911.

118. da Silva A, Kronthaler U, Meyer I, Fritsch C, Schneiderer T, Stangler T, et al. Physicochemical, functional, and pharmacologic comparability between the proposed biosimilar rituximab GP2013 and originator rituximab as the foundation for biosimilarity. J Clin Oncol. 2013;31(suppl; abstr 3075). http:// meetinglibrary.asco.org/content/116796-132.

119. Visser JM, Feuerstein I, Stangler T, Schmiederer T, Fritsch C, Schiestl M. Physicochemical and functional comparability between the proposed biosimilar rituximab GP2013 and originator rituximab. BioDrugs. 2013;27(5):495-507.

120. Hurst SI, Ryan AM, Ng C-K, Ploch SA, Finch GL, Leach MW. Nonclinical assessments demonstrating the similarity of the proposed biosimilar PF-05280586 and rituximab. Ann Rheum Dis. 2013;72:A198.

121. Hurst S, Ryan AM, Ng CK, Thompson M, Plock S, Finch GL, et al. Comparative nonclinical assessments of rituximab-EU $\left(\right.$ MabThera ${ }^{\circledR}$ ) and the potential biosimilar PF-05280586. American Association of Pharmaceutical Scientists (AAPS) National Biotechnology Conference; 20-23 May 2013; San Diego, CA; 2013: M1125.

122. Karnik S, Thompson M, De Gruttola H, Ferrari S, Gu L, Aggarwal P, et al. Characterization and comparison of PF-05280586-A proposed rituximab biosimilar to the licensed product American Association of Pharmaceutical Scientists (AAPS) National Biotechnology Conference; 2013 20-23 May 2013; San Diego, CA; 2013: M1038.

123. Jacobs I, Yin D, Melia LA, Gumbiner B, Suster M, Thomas D, et al. A phase I trial comparing PF-05280586 (a potential biosimilar) and rituximab in patients with active rheumatoid arthritis. Ann Rheum Dis. 2015;74:724.

124. Ryan AM, Sokolowski S, Collinge M, Shen A, Arrington J, Cummings $\mathrm{T}$, et al. Comparative pharmacodynamic effects of rituximab-EU (MabThera ${ }^{\circledR}$ ) and rituximab-Pfizer in cynomolgus monkeys. 52nd Annual Meeting and ToxExpo of the Society of Toxicology (SOT) 10-14 March 2013; San Antonio, TX; 2013:382.

125. Thomas D, Becker J-CP, Ng C-K. Comparison of proposed biosimilar PF-05280586 with rituximab: nonclinical and Phase I clinical assessments. Arthritis Rheum. 2013;65:S1014-S.
126. Williams J, Hutmacher MH, Zierhut M, Becker J, Gumbiner B, Spencer-Green G, et al. Assessment of clinical response in patients with rheumatic arthritis (RA) between PF-05280586, a proposed biosimilar to rituximab and two rituximab products. Clin Pharmacol Ther. 2015;97(S1):S96. doi:10.1002/cpt.52.

127. Yin D, Becker J-C, Melia L, Li R, Gumbiner B, Thomas D, et al. A Phase I pharmacokinetics trial comparing PF-05280586 (a potential biosimilar) and rituximab in subjects with active rheumatoid arthritis with active disease in TNF failures (REFLECTIONS B328-01). Ann Rheum Dis. 2014;73:497.

128. Seigelchifer M, Corley E, Fresnillo G, Pesce A, Bes C, Elise M, et al. Development of RTXM83 (a potential rituximab biosimilar): In vitro and in vivo comparability with MabThera [Abstract no. e14020]. J Clin Oncol. 2014;32 Suppl.

129. Kumar V, Vemuri S, Lella RK, Babu MN, Atluri A, Gowravaram $\mathrm{M}$, et al. Suitability of 'one assay' for immunogenicity assessment of both proposed biosimilar and innovator rituximab. American Association of Pharmaceutical Scientists National Biotechnology Conference; 2014 2-4 November 2014; San Diego, CA; 2014: M1042.

130. Lin S, Ramatlapeng D, Hanning J, Bakewell W. Comparability study of monoclonal biosimilar drug products using various analytical methods. CASS WCBP; 2014; Washington DC; 2014: 104.

131. Mekhssian K, Mess JN, Montalibet J, Garofolo F. Application of complementary HRMS methodologies for a thorough biosimilar comparability assessment. American Association of Pharmaceutical Scientists (AAPS) National Biotechnology Conference; 2015 8-10 June 2015; San Francisco, CA; 2015: T2055.

132. Roy PS, John S, Kannan S, Gujral S, Gawande J, B. B, et al. Comparison of efficacy and safety of rituximab (Mabthera) and its biosimilar (Reditux) in diffuse large b cell lymphoma (DLBCL) patients treated with chemo-immunotherapy: a retrospective analysis. 53rd National Conference of Indian Society of Hematology and Blood Transfusion (ISHBT) 2012 9-11 November 2012; Puri, India: Springer; 2012: Abstract no. 234.

133. Roy PS, Sengar M, Menon H, et al. A retrospective single centre analysis of safety, toxicity and efficacy of rituximab (original) and its biosimilar in diffuse large B-cell lymphoma patients treated with chemo-immunotherapy. European Society for Medical Oncology (ESMO) Congress; 201228 September-02 October 2012; Vienna, Austria; 2012; Abstract no. ix351.

134. Bandyopadhyay S. Efficacy and safety of rituximab-biosimilar in rheumatoid arthritis. 16th Asia Pacific League of Associations for Rheumatology (APLAR) Congress; 31 March-4 April 2014; Cebu City, Philippines; 2014:57.

135. Born TL, Huynh Q, Mathur A, Velayudhan J, Canon J, Reynhardt $\mathrm{K}$, et al. Funtional similarity assessment results comparing bevacizumab to biosimilar candidate ABP 215. Ann Oncol. 2014;25(Suppl 4):iv163-iv.

136. Hutterer K, Liu J, Martinez T, Pace D, Yates Z, Velayudhan J, et al. Analytical similarity assessment of a biosimilar to bevacizumab. WCBP Symposium of CASS; 201527 Jan 2015; Washington DC; 2015: 146

137. Markus RA, Born T, Chow V, Zhang N, Huynh Q, Maher G, et al. Functional similarity and human pharmacokinetic (PK) equivalence of $\mathrm{ABP} 215$ and bevacizumab [Abstract no. e14659]. J Clin Oncol. 2015;33.

138. ClinicalTrials.gov. Efficacy and safety study of ABP 215 compared with bevacizumab in subjects with advanced non-small cell lung cancer. 28 April 2016. Available from: https:// clinicaltrials.gov/show/NCT01966003. Accessed 2016 Jun 21.

139. ClinicalTrials.gov. A safety and efficacy study of BCD-021 with paclitaxel and carboplatin compared to Avastin with paclitaxel and carboplatin in non-small cell lung cancer. 2 Feb 2015. 
Available from: https://clinicaltrials.gov/show/NCT01763645. Accessed 2016 Jun 21.

140. ClinicalTrials.gov. Safety and efficacy study of BCD-021 compared to Lucentis ${ }^{\circledR}$ in patients with neovascular wet agerelated macular degeneration (GALATIR). 30 March 2016. Available from: https://clinicaltrials.gov/show/NCT02036723. Accessed 2016 Jun 21.

141. ClinicalTrials.gov. Bioequivalence study bevacizumab biosimilar (BEVZ92) versus bevacizumab (Avastin ${ }^{\circledR}$ ) in first-line treatment mCRC patients. 19 March 2016. Available from: https://clinicaltrials.gov/show/NCT02069704. Accessed 2016 Jun 21.

142. Grunder B. Characterization and similarity assessment of bevacizumab and a proposed biosimilar. 2014 American Association of Pharmaceutical Scientists (AAPS) Annual Meeting and Exposition; 2-6 November 2014; San Diego, CA; 2014: W5349.

143. Peraza M, Shiue M, Phenix S, Rule K, Finch GL, Thibault S, et al. Comparative nonclinical assessment of the potential biosimilar PF-06439535 and bevacizumab. 54th Annual Meeting of Society of Toxicology (SOT) 2015 22-26 March 2015; San Diego, CA; 2015: Abstract no. 129.

144. ClinicalTrials.gov. A pharmacokinetic study comparing PF-06439535 and bevacizumab In healthy male volunteers (REFLECTIONS B739-01). 14 Aug 2014. Available from: https://clinicaltrials.gov/show/NCT02031991. Accessed 2016 Jun 21.

145. ClinicalTrials.gov. A comparative study of PF-06439535 plus paclitaxel-carboplatin and bevacizumab plus paclitaxel-carboplatin patients with advanced non-squamous NSCLC. 14 June 2015. Available from: https://clinicaltrials.gov/show/ NCT02364999. Accessed 2016 Jun 21

146. Archuadze S, Shipaeva P, Dwivedi Y, Lavrovsky M, Samsonov M, Oshodi T. Pharmacokinetic profile of RPH-001, a recombinant humanized monoclonal antibody to human VEGF following administration by intravenous infusion in the cynomolgus monkey. Toxicologist. 2015;144(1):128.

147. ClinicalTrials.gov. Pharmacokinetic, safety, tolerability, and immunogenicity study of SB8 in healthy male subjects. 24 Nov 2015. Available from: https://clinicaltrials.gov/show/ NCT02453672. Accessed 2016 Jun 21.

148. ClinicalTrials.gov. A safety and efficacy study of BCD-022 with paclitaxel compared to Herceptin with paclitaxel in HER2positive metastatic breast cancer patients. $2 \mathrm{Feb} 2015$. Available from: https://clinicaltrials.gov/show/NCT01764022. Accessed 2016 Jun 21.

149. ClinicalTrials.gov. Demonstrate efficacy and safety of metastatic breast cancer (Compare). 11 Feb 2015. Available from: https://clinicaltrials.gov/show/NCT01084876. Accessed 2016 Jun 21.

150. ClinicalTrials.gov. Efficacy and safety evaluating study of CTP6 in HER2 positive early breast cancer. 17 Dec 2015. Available from: https://clinicaltrials.gov/show/NCT02162667. Accessed 2016 Jun 21.

151. Wisman L, De Cock E, Reijers J, De Visser I, De Kam M, van Os S, et al. A phase I dose escalation and bioequivalence study of a trastuzumab biosimilar (FTMB) in healthy male volunteers. European Society for Medical Oncology (ESMO) Congress; 28 September-02 October 2012; Vienna, Austria; 2012: ix103-ix4.

152. ClinicalTrials.gov. Efficacy and safety study of ABP 980 compared with trastuzumab in subjects with HER2 positive early breast cancer (Lilac). 11 May 2016. Available from: https:// clinicaltrials.gov/show/NCT01901146. Accessed 2016 Jun 21.

153. Boyle PJ, DeGruttola H, Ferrari S, Gu L, Aggarwal P, Thompson $\mathrm{M}$, et al. Characterization and comparison of PF-05280014-A proposed trastuzumab biosimilar to the licensed product. American Association of Pharmaceutical Scientists (AAPS) National Biotechnology Conference; 2013 20-22 May 2013; San Diego, CA; 2013: M1037.

154. Hurst S, Ryan A, Ng C, Thompson M, McNally J, Ploch S, et al. Comparative nonclinical assessments of trastuzumab-US and trastuzumab-EU (Herceptin $\left.{ }^{\circledR}\right)$ and the potential biosimilar PF05280014 American Association of Pharmaceutical Scientists National Biotechnology Conference; 20-23 May 2013; San Diego, CA; 2013: M1124.

155. Ryan AM, Hurst S, McNally JM, Lorello LG, Finch GL, Leach MW, et al. Comparative pharmacokinetics of trastuzumab-US and trastuzumab-EU and the potential biosimilar trastuzumabPfizer in male CD-1 mice. Eur J Cancer. 2012;48:98.

156. Jacobs IA, Ewesuedo R, Yin D, Li R, Hurst S, Ryan AM, et al. Development of PF-05280014, a potential biosimilar to trastuzumab [abstract]. American Society of Clinical Onology (ASCO) 2015 Annual Meeting; 201529 May-2 June 2015; Chicago, IL; 2015:618.

157. Ricart AD, Zacharchuk C, Reich SD, Meng X, Barker KB, Taylor CT, et al. A Phase I pharmacokinetics trial comparing PF-05280014 and trastuzumab in healthy volunteers (reflections B327-01). 35th Annual CTRC-AACR San Antonio Breast Cancer Symposium (SABCS); 4-8 December 2012; San Antonio, TX: Cancer Res; 2012: Abstract no. OT1105.

158. Yin D, Barker KB, Li R, Meng X, Reich SD, Ricart AD, et al. A Phase I pharmacokinetics trial comparing PF-05280014 (a potential biosimilar) and trastuzumab in healthy volunteers (REFLECTIONS B327-01). J Clin Oncol. 2013;31 Suppl: Abstract no. 171

159. Yin D, Cai CH, Taylor CT, Zacharchuk CM, Rudin D, Reich $\mathrm{SD}$, et al. Immunogenicity assessment of PF-05280014, a potential biosimilar to trastuzumab, in healthy subjects (REFLECTIONS B327-01). Eur J Cancer. 2013;49:S176-7.

160. Ewesuedo R, Barker KB, Taylor CT, Jacobs I. A Phase 3 randomized, double-blind trial comparing PF-05280014 + paclitaxel vs trastuzumab + paclitaxel for treatment of HER2 + metastatic breast cancer. Cancer Res. 2013;73(24).

161. Jacobs I, Coiro J, Hilton F, Orazem J, Abbas R, Zacharchuk C. A Phase 3 randomized, double-blind trial comparing PF-05280014 + docetaxel and carboplatin vs. trastuzumab + docetaxel and carboplatin for neoadjuvant treatment of operable HER2 + breast cancer. Cancer Res. 2015;75(9 Suppl):Abstract no. OT3-1-02-OT3-1.

162. ClinicalTrials.gov. A study evaluating the safety of PF-05280014 and trastuzumab In healthy male volunteers (REFLECTIONS B327-06). 21 April 2014. Available from: https://clinicaltrials.gov/show/NCT02015156. Accessed 2016 Jun 21.

163. ClinicalTrials.gov. Pharmacokinetic, safety, tolerability and immunogenicity study of SB3 in healthy male subjects. 19 May 2014. Available from: https://clinicaltrials.gov/show/ NCT02075073. Accessed 2016 Jun 21.

164. ClinicalTrials.gov. A study to compare the effect of SB3 and Herceptin ${ }^{\circledR}$ in women with HER2 positive breast cancer. 2 May 2016. Available from: https://clinicaltrials.gov/show/ NCT02149524. Accessed 2016 Jun 21.

165. ClinicalTrials.gov. Safety and efficacy study of BCD-020 in therapy of non-Hodgkin's lymphoma. 12 Jan 2016. Available from: https://clinicaltrials.gov/show/NCT01701232. Accessed 2016 Jun 21.

166. ClinicalTrials.gov. Study of safety and efficacy of BCD-020 comparing to MabThera in patients with rheumatoid arthritis (BIORA). 12 Jan 2016. Available from: https://clinicaltrials. gov/show/NCT01759030. Accessed 2016 Jun 21.

167. ClinicalTrials.gov. Efficacy, pharmacokinetics, and safety of BI 695500 in patients with rheumatoid arthritis. 6 April 2016. 
Available from: https://www.clinicaltrials.gov/ct2/show/record/ NCT01682512. Accessed 2016 Jun 21.

168. ClinicalTrials.gov. To demonstrate equivalence of pharmacokinetics and noninferiority of efficacy for CT-P10 in comparison with Rituxan (rituximab). 11 Feb 2016. Available from: https:// clinicaltrials.gov/show/NCT02162771. Accessed 2016 Jun 21.

169. ClinicalTrials.gov. To compare efficacy and safety between CTP10 and Rituxan in patients with low tumour burden follicular lymphoma. 25 April 2016. Available from: https://clinicaltrials. gov/show/NCT02260804. Accessed 2016 Jun 21.

170. ClinicalTrials.gov. PK similarity prospective phase 3 study in patients with rheumatoid arthritis (rituximab). 3 Nov 2015. Available from: https://clinicaltrials.gov/show/NCT02149121. Accessed 2016 Jun 21.

171. ClinicalTrials.gov. Long-term efficacy and safety of CT-P10 in patients with RA. 25 Nov 2015. Available from: https:// clinicaltrials.gov/show/NCT01873443. Accessed 2016 Jun 21.

172. ClinicalTrials.gov. GP2013 in the treatment of RA patients refractory to or intolerant of standard therapy. 20114 Feb 2016. Available from: https://clinicaltrials.gov/show/NCT01274182. Accessed 2016 Jun 21.

173. ClinicalTrials.gov. GP2013 in the treatment of patients with previously untreated, advanced stage follicular lymphoma (ASSIST_FL). 15 March 2016. Available from: https:// clinicaltrials.gov/show/NCT01419665. Accessed 2016 Jun 21.

174. ClinicalTrials.gov. GP2013 treatment in patients with active rheumatoid arthritis, previously treated with Rituxan ${ }^{\circledR}$ or MabThera ${ }^{\circledR}$ (ASSIST-RT). 3 May 2016 Available from: https:// clinicaltrials.gov/show/NCT02514772. Accessed 2016 Jun 21.

175. ClinicalTrials.gov. A study Of PF-05280586 (rituximab-Pfizer) or MabThera ${ }^{\circledR}$ (rituximab-EU) for the first-line treatment of patients with CD20-positive, low tumor burden, follicular lymphoma (REFLECTIONS B328-06). 1 June 2016. Available from: https://clinicaltrials.gov/show/NCT02213263. Accessed 2016 Jun 21.

176. ClinicalTrials.gov. Study of RTXM83 plus CHOP chemotherapy versus a rituximab plus CHOP therapy in patients with non Hodgkin's lymphoma. 19 May 2016. Available from: https:// clinicaltrials.gov/show/NCT02268045. Accessed 2016 Jun 21.

177. Born T, Velayudhan J, Chen Y, Thomas H, Pastula C, Maher G, et al. Demonstration of functional similarity comparing adalimumab to biosimilar candidate ABP 501. Arthritis Rheum. 2014;66(S10):S661

178. Born T, Velayudhan J, Mathur A, Chen YF. Demonstration of functional equivalence of proposed biosimilar ABP 501 to adalimumab. 23rd European Academy of Dermatology and Venereology (EADV) Congress; 2014 8-12 Oct 2014; Amsterdam, The Netherlands; 2014: P337.

179. Kaur P, Chow V, Zhang N, Markus R. Relationship between pharmacokinetics and anti-drug antibody status of ABP 501, a biosimilar candidate to adalimumab. Ann Rheum Dis. 2015;74:714.

180. Kaur PP, Chow V, Zhang N, Moxness M, Markus R. Pharmacokinetic equivalence of ABP 501 relative to adalimumab: results from a randomized, single-blind, single-dose, parallel group study in healthy subjects. Arthritis Rheum. 2014;66:S661-2.

181. Liu J, Hutterer K, Eris T, Abel J, Jiang Y, Li C, et al. Analytical similarity assessment of a biosimilar to adalimumab. American Association of Pharmaceutical Scientists (AAPS) Annual Meeting; 2-4 November 2014; San Diego, CA; 2014: W5350.

182. Tatarewicz S, Miller M, Zhou L, Moxness M. Biosimilar immunogenicity assessment strategy American Association of Pharmaceutical Scientists (AAPS) National Biotechnology Conference; 2-4 November 2014; San Diego, CA; 2014: Abstract no. M1069.
183. ClinicalTrials.gov. Long-term safety and efficacy of ABP 501 in subjects with moderate to severe rheumatoid arthritis. 21 April 2016. Available from: https://clinicaltrials.gov/show/ NCT02114931. Accessed 2016 Jun 21.

184. ClinicalTrials.gov. Study to compare efficacy and safety of ABP 501 and adalimumab (Humira ${ }^{\circledR}$ ) in adults with moderate to severe plaque psoriasis. 19 May 2015. Available from: https:// clinicaltrials.gov/show/NCT01970488. Accessed 2016 Jun 21.

185. ClinicalTrials.gov. Efficacy and safety study of ABP 501 compared to adalimumab in subjects with moderate to severe rheumatoid arthritis (RA). 14 May 2015. Available from: https:// clinicaltrials.gov/show/NCT01970475. Accessed 2016 Jun 21.

186. ClinicalTrials.gov. Comparative clinical trial to evaluate pharmacokinetics, tolerance and safety of BCD-057 and Humira in healthy volunteers. 15 April 2016. Available from: https:// clinicaltrials.gov/show/NCT02395055. Accessed 2016 Jun 21.

187. ClinicalTrials.gov. BI 695501 compared to adalimumab in patients with active rheumatoid arthritis. 6 June 2016. Available from: https://clinicaltrials.gov/ct2/show/record/NCT02137226. Accessed 2016 Jun 21.

188. ClinicalTrials.gov. Comparison of CHS-1420 versus Humira in subjects with chronic plaque psoriasis (PsOsim). 8 March 2016. Available from: https://clinicaltrials.gov/show/NCT02489227. Accessed 2016 Jun 21.

189. Kronthaler U, Baron M, Poetzl J, Da Silva A. Preclinical PK and safety assessment of the proposed adalimumab biosimilar GP2017, compared to Humira ${ }^{\circledR}$. Ann Rheum Dis. 2014;73(Suppl 2):943. doi:10.1136/annrheumdis-2014-eular. 1545.

190. Kronthaler U, da Silva A, Poetzl J, Seliskar M, Baron M. Similar preclinical pharmacokinetics of the proposed biosimilar adalimumab GP2017 and originator adalimumab upon single and multiple administrations. J Am Acad Dermatol. 2014;70:AB190.

191. Kronthaler U, Hofmann HP, Poetzl J, Demin I, Didier R, da Silva A. Characterization of efficacy and biomarker response of the proposed adalimumab biosimilar GP2017 compared to originator adalimumab in a humanized mouse model. 23rd Congress of the European Acadamy of Dermatology and Venereology (EADV); 2014 8-12 October 2014; Amsterdam, The Netherlands; 2014: P338.

192. ClinicalTrials.gov. Study to demonstrate equivalent efficacy and to compare safety of biosimilar adalimumab (GP2017) and Humira (ADACCESS). 9 June 2016. Available from: https:// clinicaltrials.gov/show/NCT02016105. Accessed 2016 Jun 21.

193. ClinicalTrials.gov. Pharmacokinetics and safety study of LBAL in healthy subjects. 12 June 2015. Available from: https:// clinicaltrials.gov/ct2/show/record/NCT02206867. Accessed 2016 Jun 21.

194. Derzi M, Ripp SL, Ng C, Shoieb AM, Finch G, Lorello LG, et al. Comparative nonclinical assessments of the potential biosimilar PF-06410293 and adalimumab. 53rd Annual Meeting of the Society of Toxicology; 2014 23-27 March 2014; Phoenix, AZ; 2014:70.

195. Wang X, Zhou J, Ma Q, Buckery R, Cai CHS, Chen L. Development and validation of a cell-based neutralizing antiadalimumab antibody detection methods for adalimumab biosimilar program. American Association of Pharmaceutical Scientists (AAPS) National Biotechnology Conference; 2-4 November 2014; San Diego, CA; Abstract no. M1023.

196. ClinicalTrials.gov. A study of PF-06410293 following subcutaneous administration using a prefilled syringe or a prefilled pen In healthy adult subjects (B538-05). 3 June 2016. Available from: https://clinicaltrials.gov/ct2/show/record/NCT02572245?term= PF-06410293\&rank=1. Accessed 2016 Jun 21.

197. ClinicalTrials.gov. Study of PF-06410293 and adalimumab In healthy subjects (REFLECTIONS B538-01). 13 Feb 2014. 
Available from: https://clinicaltrials.gov/ct2/show/record/ NCT01870986?term=PF-06410293\&rank=3. Accessed 2016 Jun 21.

198. ClinicalTrials.gov. A study Of PF-06410293 (adalimumab-Pfizer) and adalimumab (Humira) In healthy subjects (REFLECTIONS B538-07)) (B538-07). 10 April 2015. Available from: https://clinicaltrials.gov/ct2/show/record/NCT02237729?term= PF-06410293\&rank=4. Accessed 2016 Jun 21.

199. ClinicalTrials.gov. A study Of PF-06410293 (adalimumab-Pfizer) and adalimumab (Humira) In combination with methotrexate In subjects with active rheumatoid arthritis (REFLECTIONS B538-02). 13 June 2016. Available from: https://clinicaltrials.gov/ct2/show/record/NCT02480153?term= PF-06410293\&rank=2. Accessed 2016 Jun 21.

200. ClinicalTrials.gov. Pharmacokinetics, safety, and tolerability study of the pen and PFS of SB5 in healthy subjects. 14 Dec 2015. Available from: https://clinicaltrials.gov/show/ NCT02326233. Accessed 2016 Jun 21.

201. ClinicalTrials.gov. A study comparing SB5 to Humira ${ }^{\circledR}$ in subjects with moderate to severe rheumatoid arthritis despite methotrexate therapy. 2 Dec 2015. Available from: https:// clinicaltrials.gov/show/NCT02167139. Accessed 2016 Jun 21.

202. ClinicalTrials.gov. Comparative evaluation of pharmacokinetics and safety of BCD-055 and Remicade in patients with ankylosing spondylitis. 3 May 2016. Available from: https:// clinicaltrials.gov/show/NCT02359903. Accessed 2016 Jun 21.

203. Kay J, Chopra A, Chandrashekara S, Olakkengil D, Bhojani K, Bhatia G, et al. Secondary efficacy outcomes from a Phase 3 study support clinical equivalence between BOW015 and infliximab in patients with active rheumatoid arthritis on stable methotrexate doses. Ann Rheum Dis. 2015;74(Suppl 2):1034. doi:10.1136/annrheumdis-2015-eular.4286

204. Kay J, Chopra A, Lassen C, Shneyer L, Wyand M. BOW015, A biosimilar infliximab: Disease activity and disability outcomes from a Phase 3 active comparator study in ptients with active rheumatoid arthritis on stable methotrexate doses. Ann Rheum Dis. 2015;74:462-3.

205. Kay J, Lassen C, Trokan L, Wyand M. Safety profile of BOW015, a biosimilar infliximab, in healthy subjects and patients with active rheumatoid arthritis. Ann Rheum Dis. 2015;74:706. doi:10.1136/annrheumdis-2015-eular.4107.

206. Kay J, Wyand M, Chandrashekara S, Olakkengil DJ, Bhojani K, Bhatia G, et al. BOW015, a biosimilar infliximab, in patients with active rheumatoid arthritis on stable methotrexate doses: 54-week results of a randomized, double-blind, active comparator study. Arthritis Rheum. 2014;66:S1-S1402. http:// acrabstracts.org/abstract/bow015-a-biosimilar-infliximab-inpatients-with-active-rheumatoid-arthritis-on-stable-methotrexatedoses-54-week-results-of-a-randomized-double-blind-activecomparator-study/.

207. Lambert J, Wyand M, Lassen C, Shneyer L, Thomson E, Kay J. Pharmacokinetic results from a Phase 1, single-centre, doubleblind, randomised, single-dose, parallel group study comparing $5 \mathrm{MG} / \mathrm{KG}$ IV infusion of BOW015 and reference infliximab in healthy male volunteers. Ann Rheum Dis. 2015;74 Suppl 2:462.

208. Andrick B, Stroyne K, Kamal K, Meng W. Predicting immunogenicity of infliximab: Pharmacoeconomic implications for biosimilars. American Pharmacists Association (APhA) 2014 Annual Meeting and Exposition; 2014 28-31 March 2014; Orlando, FL: e185.

209. Braun J, Baraliakos X, Kudrin A, Kim H, Lee SJ. Striking discrepancy in the development of anti-drug antibodies (ADA) in patients with rheumatoid arthritis (RA) and ankylosing spondylitis (AS) in response to infliximab (INF) and its biosimilar CT-P13. Arthritis Rheum. 2014;66:3538-9.
210. Braun J, Park W, Yoo DH, Suh CH, Shim SC, Lee SJ, et al. What intrinsic and extrinsic factors affect the developement of anti-drug antibody to innovator infliximab and its biosimilar CTP13 in rheumatoid arthritis and ankylosing spondylitis. Ann Rheum Dis. 2015;74:463-4.

211. Brodszky V, Gulacsi L, Balogh O, Baji P, Rencz F, Péntek M. Budget impact analysis of biosimilar infliximab for the treatment of Crohn's disease in six Central Eastern European countries. Value Health. 2014;17(7):A364.

212. Jha A, Upton A, Dunlop WCN. Budget impact analysis of introducing biosimilar infliximab for the treatment of auto immune disorders in five European countries. Value Health. 2014;7(17):A525.

213. Jung SK, Lee KH, Jeon JW, Lee JW, Kwon BO, Kim YJ, et al. Physicochemical characterization of Remsima ${ }^{\circledR}$. MAbs. 2014;6:1163-77.

214. Kang HW, Lim YJ, Kim JH, Kang Y-S. An experience of antiTNF biosimilar, CT-P13 use: Clinical efficacy, safety and interchangeability in inflammatory bowel disease; A pilot study. J Crohns Colitis. 2014;Suppl 1(8):S303.

215. Kim J, Hong J, Kudrin A. 5 Year budget impact analysis of biosimilar infliximab for the treatment of rheumatoid arthritis in UK, Italy, France and Germany. Arthritis Rheum. 2014;66(S10):S512.

216. Kim J, An Hong J, Kudrin A. 5 year budget impact analysis of CT-P13 (infliximab) for the treatment of Crohn's Disease in UK, Italy and France [P137]. J Crohns Colitis. 18-21 February 2015;9(Suppl 1):S144-5.

217. McCarthy G, Bitoun CE, Guy H. Introduction of an infliximab biosimilar (CT-P13): a five-year budget impact analysis for the treatment of rheumatoid arthritis in Ireland. Value Health. 2013;7(16):A558

218. Park W, Hrycaj P, Jeka S, Kovalenko V, Lysenko G, Miranda P, et al. A randomised, double-blind, multicentre, parallel-group, prospective study comparing the pharmacokinetics, safety, and efficacy of CT-P13 and innovator infliximab in patients with ankylosing spondylitis: the PLANETAS study. Ann Rheum Dis. 2013;72(10):1605-12.

219. Park W, Hrycaj P, Kovalenko V, Miranda P, Gutierrez-Ureña S, Lee $\mathrm{Y}$, et al. A randomized, double-blind, phase 1 study demonstrates equivalence in pharmacokinetics, safety, and efficacy of CT-P13 and infliximab in patients with ankylosing spondylitis. Ann Rheum Dis. 2012;71:111.

220. Park W, Miranda P, Brzosko M, Wiland P, Gutierrez-Urena S, Mikazane H, et al. Efficacy and safety of CT-P13 (infliximab biosimilar) over two years in patients with ankylosing spondylitis: comparison between continuing with CT-P13 and switching from infliximab to CT-P13. Arthritis Rheum. 2013;65:3326.

221. Park W, Yoo DH, Szántó S, Berghea F, Brzosko M, Wiland P, et al. Clinical response of disease activity, disability and mobility indices in relation to anti-drug antibody in the PLANETAS. Ann Rheum Dis. 2014;73:121. doi:10.1136/ annrheumdis-2014-eular.3804.

222. Pierri CL, Cetrone M, Punzi G, Tricarico D. Therapeutic antiTNF alpha antibodies: structure-activity investigations. FASEB J. 2015;29(1 Suppl):941.9.

223. Yoo DH. Disease activity assessment using the DAS28, CDAI and SDAI and effect of anti-drug antibody on clinical response in a randomised, double-blind, comparative trial of CT-P13 and the innovator infliximab: PLANETRA study. Ann Rheum Dis. 2014;72.

224. Yoo D, Miranda P, Piotrowski M, Ramiterre E, Kovalenko V, Prodanovic N, et al. A randomized, double-blind, Phase 3 study demonstrates clinical equivalence of CT-P13 to infliximab when 
co-administered with methotrexate in patients with active rheumatoid arthritis. Ann Rheum Dis. 2012;71:359.

225. Yoo D, Park W, Miranda P, Piotrowski M, Ramiterre E, Shevchuk S, et al. Inhibition of radiographic progression and its association with clinical parameters in RA patients treated with CT-P13 and innovator infliximab in PLANETRA study. Ann Rheum Dis. 2014;73:234-5.

226. Yoo DH, Prodanovic N, Jaworski J, Miranda P, Ramiterre EB, Lanzon A. Efficacy and safety of CT-P13 (infliximab biosimilar) over two years in patients with rheumatoid arthritis: comparison between continued CT-P13 and switching from infliximab to CT-P13. American College of Rheumatology/Association of Rheumatology Health Professionals (ACR/ARHP) Annual Meeting 25-30 October 2013; San Diego, CA: 26-9.

227. Yoo DH, Racewicz A, Brzezicki J, Yatsyshyn R, Arteaga ET, Baranauskaite A, et al. A Phase 3 randomised controlled trial to compare CT-P13 with infliximab in patients with active rheumatoid arthritis: 54 week results from the PLANETRA study. Ann Rheum Dis. 2013;72:A73.

228. Yoo DH, Shevchuk S, Ramiterre E, Kovalenko V, Tee M, Tobias Arteaga E, et al. Local tuberculosis incidence affects the rate of positive conversion in the quantiferon (R)-tb gold test among patients receiving infliximab or CT-P13 therapy. Ann Rheum Dis. 2013;72:426-7.

229. Yoo DH, Yagensky A, Toncheva A, Ruiz Santacruz O, Cons Molina F, Bae Y, et al. Impact of CT-P13 and originator infliximab treatment on quality of life derived from the health assessment questionnaire (HAQ) and short-form 36 (SF-36) from a randomized, double-blind trial in patients with active RA. Arthritis Rheum. 2013;65(Suppl 10):2392.

230. Yoon Suk J, Park DI, Kim YH, Seo PJ, Kim JW, et al. Efficacy and safety of infliximab's biosimilar (REMSIMA) for IBD. J Crohns Colitis. 18-21 February 2015;9 Suppl 1:S340-S50.

231. ClinicalTrials.gov. Demonstrate noninferiority in efficacy and to assess safety of CT-P13 in patients with active Crohn's Disease. 11 Feb 2016. Available from: https://clinicaltrials.gov/show/ NCT02096861. Accessed 2016 Jun 21.

232. ClinicalTrials.gov. Efficacy and safety of infliximab-biosimilar (Inflectra) compared to infliximab-innovator (Remicade) in patients with inflammatory bowel disease in remission: the SIMILAR trial (SIMILAR). 21 May 2015. Available from: https://clinicaltrials.gov/show/NCT02452151. Accessed 2016 Jun 21.

233. ClinicalTrials.gov. The NOR-SWITCH study (NOR-SWITCH). 17 June 2016. Available from: https://clinicaltrials.gov/show/ NCT02148640. Accessed 2016 Jun 21.

234. Johnson T, Derzi M, Bolt M, Conlon H, Kirchhoff C, Lorello L, et al. Comparative nonclinical assessments of marketed infliximab presentations (Remicade) and the potential biosimilar PF06438179. American Association of Pharmaceutical Scientists (AAPS) National Biotechnology Conference; 2-4 November 2014; San Diego, CA: W3065.

235. McClellan JE, Udata C, Yin D, Salts S, Johnson TR, Derzi M, et al. Comparative structural, functional, nonclinical, and phase 1 similarity assessments of PF-06438179, a potential biosimilar to infliximab, and marketed reference products. J Crohns Colitis. 2015;2015(9 Suppl 1):S94-5.

236. Sharpe P, Saati A, Koob S, Gu L, Aggarwal P, Porter T, et al. Characterization and similarity assessment of infliximab and PF-06438179: A proposed biosimilar. American Association of Pharmaceutical Scientists (AAPS) National Biotechnology Conference; 2-4 November 2014; San Diego, CA: Abstract no. T2022.

237. Udata C, Yin D, Cai C-H, Salts S, Hua SY, Rehman MI, et al. Immunogenicity assessment of PF-06438179, a potential biosimilar to infliximab, in healthy volunteers. Arthritis Rheum. 2014;66:S660.

238. Udata C, Yin DHCC, Hua SY, Salts S, Rehman ML, Meng X. Immunogenicity assessment of PF-06438179, a potential biosimilar to infliximab, in healthy volunteers. Ann Rheum Dis. 2015;74:702. http://acrabstracts.org/abstract/immunogenicityassessment-of-pf-06438179-a-potential-biosimilar-toinfliximab-in-healthy-volunteers/.

239. Yin D, Udata C, Hua S, Salts S, Meng X, Johnson TR, et al. Comparative assessments of PF-06438179, a potential biosimilar, and infliximab in a Phase 1 pharmacokinetic study. Gastroenterology. 2015;148(4):S-642.

240. ClinicalTrials.gov. A Study of PF-06438179 (infliximab-Pfizer) and infliximab in combination with methotrexate in subjects with active rheumatoid arthritis (REFLECTIONS B537-02). 25 March 2016. Available from: https://clinicaltrials.gov/show/ NCT02222493. Accessed 2016 Jun 21.

241. Choe JY, Prodanovic N, Niebrzydowski J, Staykov I, Dokoupliova E, Baranauskaite A, et al. A randomised, double-blind, phase III study comparing SB2, an infliximab biosimilar, to the infliximab reference product $\left(\right.$ Remicade $\left.^{\circledR}\right)$ in patients with moderate to severe rheumatoid arthritis despite methotrexate therapy. Ann Rhuem Dis. 2015;74:706-7.

242. ClinicalTrials.gov. Comparison of CHS-0214 to Enbrel (etanercept) in patients with rheumatoid arthritis (RA) (CHS-021402). 5 Jan 2016. Available from: https://clinicaltrials.gov/show/ NCT02115750. Accessed 2016 Jun 21.

243. ClinicalTrials.gov. A long term safety extension study (CHS0214-05). 17 May 2016. Available from: https://clinicaltrials. gov/show/NCT02486939. Accessed 2016 Jun 21.

244. ClinicalTrials.gov. Comparison of CHS-0214 to Enbrel (etanercept) in patients with chronic plaque psoriasis (PsO). 10 Aug 2015. Available from: https://clinicaltrials.gov/show/ NCT02134210. Accessed 2016 Jun 21.

245. Gu NY, Kim BR, Kim BH, Kim JW, Song DH, Shin SG, et al. Comparative pharmacokinetics/tolerability of TUNEX and ENBREL in healthy Korean volunteers. Clin Pharmacol Ther. 2010;87:S93-S.

246. ClinicalTrials.gov. A prospective, randomized, double-blind, placebo-controlled, parallel-group, multicentre, phase III study to evaluate the efficacy and safety of ENIA11 in combination with DMARDs versus DMARDs alone in patients with rheumatoid arthritis. 12 April 2016. Available from: https:// clinicaltrials.gov/show/NCT01787149. Accessed 2016 Jun 21.

247. da Silva A, Kronthaler U, Fritsch C, Poetzl J, Rohde A, Papandrikopoulou A, et al. Target-directed development of a proposed etanercept biosimilar, GP2015: comparability of in vitro target binding and neutralization, and in vivo efficacy and pharmacokinetics with the reference product etanercept at the pre-clinical level. Congress of the European Academy of Dermatology and Venereology (EADV); 2-6 October 2013; Istanbul, Turkey: P304.

248. da Silva A, Kronthaler U, Fritsch C, Poetzl J, Rohde A, Papandrikopoulou A, et al. Target-directed development of a proposed biosimilar etanercept, GP2015: Comparability of in vitro target binding and pre-clinical efficacy and pharmacokinetics. Arthritis Rheum. 2013;65(S10):S794.

249. ClinicalTrials.gov. Study to demonstrate equivalent efficacy and to compare safety of biosimilar etanercept (GP2015) and Enbrel (EGALITY). 26 Oct 2015. Available from: https://clinicaltrials. gov/show/NCT01891864. Accessed 2016 Jun 21]

250. Bae SC, Lee SR, Ahn Y. Quality of life assessments in Korean patients with rheumatoid arthritis (RA): An analysis from the Phase III trial to evaluate equivalence of the etanercept biosimilar HD203 and Enbrel ${ }^{\circledR}$ in combination with 
methotrexate (MTX) in patients with RA; The HERA study. Value Health. 2014;7(17):A374.

251. ClinicalTrials.gov. Safety and pharmacokinetic characteristics of HD203 liq. in healthy subjects. 3 July 2013. Available from: https:// clinicaltrials.gov/show/NCT01431404. Accessed 2016 Jun 21.

252. ClinicalTrials.gov. Safety and pharmacokinetic characteristics of HD203 liquid in healthy male volunteers. 13 July 2014. Available from: https://clinicaltrials.gov/show/NCT01894412. Accessed 2016 Jun 21

253. ClinicalTrials.gov. Study to compare the safety and pharmacokinetic characteristics of LBEC0101 $25 \mathrm{mg}$ with those of Enbrel $^{\circledR} .17$ Feb 2011. Available from: https://clinicaltrials.gov/ show/NCT01145950. Accessed 2016 Jun 21.

254. ClinicalTrials.gov. A study comparing LBEC0101 to Enbrel ${ }^{\circledR}$ in subjects with active rheumatoid arthritis despite methotrexate therapy. 5 Jan 2016. Available from: https://clinicaltrials.gov/ show/NCT02357069. Accessed 2016 Jun 21.

255. Ebbers HC, van Meer PJ, Moors EH, Mantel-Teeuwisse AK, Leufkens HG, Schellekens H. Measures of biosimilarity in monoclonal antibodies in oncology: the case of bevacizumab. Drug Discov Today. 2013;18(17-18):872-9.

256. Li E, Subramanian J, Anderson S, Thomas D, McKinley J, Jacobs IA. Development of biosimilars in an era of oncologic drug shortages. Drug Des Devel Ther. 2015;9:3247-55.

257. Biosimilars Dhingra K. The industry perspective. J Crohns Colitis. 2009;3(Suppl 1):78.

258. Beck A, Sanglier-Cianferani S, Van Dorsselaer A. Biosimilar, biobetter, and next generation antibody characterization by mass spectrometry. Anal Chem. 2012;84(11):4637-46.

259. Kurbanova EK, Chulkova TY, Byrikhina DV, Dano AO, Nikolaeva VA, Gusarov DA. PHARMA-2020: technological aspects of production of some strategical biopharmaceuticals. J Biopharm. 2012;4:21-45.

260. Guo W, Chen Y. J W. Considerations for biosimilar monoclonal antibody development: Lessons learned from clinical trials of trastuzumab. Chinese. J Cancer Biotherapy. 2014;4:359-65.

261. Nelson KM, Gallagher PC. Biosimilars lining up to compete with Herceptin-opportunity knocks. Expert Opin Ther Pat. 2014;24(11):1149-53.

262. No authors listed. What are biosimilars and are they important? Drug Ther Bull. 2013;51(5):57-60.

263. Thill M. New frontiers in oncology: biosimilar monoclonal antibodies for the treatment of breast cancer. Expert Rev Anticancer Ther. 2015;15(3):331-8.

264. Araujo F, Cordeiro I, Teixeira F, Goncalves J, Fonseca JE. Pharmacology of biosimilar candidate drugs in rheumatology: a literature review. Acta Reumatol Port. 2014;39(1):19-26.

265. da Silva A, Grau R, Stangler T, et al. Comprehensive targetdirected approach for the development of a highly-comparable rituximab biosimilar. Ann Rheum Dis. 2012;71:718.

266. Smolen J, Landewe R, Breedveld FC, Buch M, Burmester G, Dougados M. EULAR recommendations for the managements of rheumatoid arthritis with synthetic and biological diseasemodifying antirheumatic drugs: 2013 Update. Rheumatologia. 2014;28:1-25.

267. Smolen JS, Landewe R, Breedveld FC, Buch M, Burmester G, Dougados $\mathrm{M}$, et al. EULAR recommendations for the management of rheumatoid arthritis with synthetic and biological disease-modifying antirheumatic drugs: 2013 update. Ann Rheum Dis. 2014;73(3):492-509.

268. Smolen JS, van der Heijde D, Machold KP, Aletaha D, Landewe R. Proposal for a new nomenclature of disease-modifying antirheumatic drugs. Ann Rheum Dis. 2014;73(1):3-5.

269. Brown PM, Isaacs JD. Rheumatoid arthritis: an evolutionary force in biologics. Curr Pharm Des. 2015;21(17):2170-8.
270. Cragg MS. CD20 antibodies: doing the time warp. Blood. 2011;118(2):219-20.

271. Goel N, Chance K. The biosimilar landscape: a systematic review of its current status. Arthritis Rheum. 2014;74:S662.

272. Nam JL, Ramiro S, Gaujoux-Viala C, Takase K, Leon-Garcia $\mathrm{M}$, Emery $\mathrm{P}$, et al. Efficacy of biological disease-modifying antirheumatic drugs: a systematic literature review informing the 2013 update of the EULAR recommendations for the management of rheumatoid arthritis. Ann Rheum Dis. 2014;73(3):516-28.

273. Rioufol C, Salles G. Biosimilar monoclonal antibodies in lymphoma: a critical appraisal. Expert Rev Anticancer Ther. 2015;15(5):569-78.

274. Vital EM, Kay J, Emery P. Rituximab biosimilars. Expert Opin Biol Ther. 2013;13(7):1049-62.

275. Kay J. Biosimilars: a regulatory perspective from America. Arthritis Res Ther. 2011;13(3):112.

276. Kudrin A, Knezevic I, Joung J, Kang HN. Case studies on clinical evaluation of biosimilar monoclonal antibody: Scientific considerations for regulatory approval. Biologicals. 2015;43(1):1-10.

277. Chamberlain P. Assessing immunogenicity of biosimilar therapeutic monoclonal antibodies: regulatory and bioanalytical considerations. Bioanalysis. 2013;5(5):561-74.

278. Urbano PC, Soccol VT, Azevedo VF. Apoptosis and the FLIP and NF-kappa B proteins as pharmacodynamic criteria for biosimilar TNF-alpha antagonists. Biologics. 2014;8:211-20.

279. Thivolet M, Remuzat C, Kornfeld A, Toumi M. Dispensation channels of anti-TNFs in inflammatory bowel disease. Value Health. 2013;16:A501.

280. Arguelles-Arias F, Barreiro-de-Acosta M, Carballo F, Hinojosa J, Tejerina T. Joint position statement by "Sociedad Espanola de Patologia Digestiva" (Spanish Society of Gastroenterology) and "Sociedad Espanola de Farmacologia" (Spanish Society of Pharmacology) on biosimilar therapy for inflammatory bowel disease. Rev Esp Enferm Dig. 2013;105(1):37-43.

281. Nast A, Rosumeck S, Seidenschnur K. Biosimilars: a systematic review of published and ongoing clinical trials of antipsoriatics in chronic inflammatory diseases. J Dtsch Dermatol Ges. 2015 Ar;13(4):294-300.

282. Lawrance IC. Early investigational TNF receptor antagonists for the treatment of ulcerative colitis. Expert Opin Investig Drugs. 2015;24(6):761-8.

283. Willrich MA, Murray DL, Snyder MR. Tumor necrosis factor inhibitors: clinical utility in autoimmune diseases. Transl Res. 2015;165(2):270-82.

284. Radtke MA, Augustin M. Biosimilars in psoriasis: what can we expect? J Dtsch Dermatol Ges. 2014;12(4):306-12.

285. Kasap Y, Aydinkarahaliloglu DN, Aykac E, et al. The drugs monitored by TUFAM with Risk Management Plan (RMP). Drug Saf. 2011;34:906-7.

286. Braun J, Kudrin A. Progress in biosimilar monoclonal antibody development: the infliximab biosimilar CT-P13 in the treatment of rheumatic diseases. Immunotherapy. 2015;7(2):73-87.

287. McKeage K. A review of CT-P13: an infliximab biosimilar. BioDrugs. 2014;28(3):313-21.

288. Feagan BG, Choquette D, Ghosh S, Gladman DD, Ho V, Meibohm B, et al. The challenge of indication extrapolation for infliximab biosimilars. Biologicals. 2014;42(4):177-83.

289. Annese V, Vecchi M. Use of biosimilars in inflammatory bowel disease: Statements of the Italian Group for Inflammatory Bowel Disease. Dig Liver Dis. 2014;46(11):963-8.

290. New treatment option for chronic inflammatory diseases: Remsima-the first biosimilar infliximab. Verdauungskrankheiten. 2015;33(2):108-9. 
291. Ainsworth M. Is extrapolation of safety and efficacy data possible? Karger. 2015;34:107-12.

292. Castaneda-Hernandez G, Szekanecz Z, Mysler E, Azevedo VF, Guzman R, Gutierrez M, et al. Biopharmaceuticals for rheumatic diseases in Latin America, Europe, Russia, and India: innovators, biosimilars, and intended copies. Joint Bone Spine. 2014;81(6):471-7.

293. Dorner T, Kay J. Biosimilars in rheumatology: current perspectives and lessons learnt. Nat Rev Rheumatol. 2015;11(12):713-24.

294. Dreesen E, Gils A. Neutralisation of soluble tumor necrosis factor. Front Gastrointest Res. 2015;34:83-9.

295. Gomollon F. Biosimilars: are they bioequivalent? Dig Dis. 2014;32(Suppl 1):82-7.

296. Gomollon F. Biosimilars in inflammatory bowel disease: ready for prime time? Curr Opin Gastroenterol. 2015;31(4):290-5.

297. Hlavaty T, Letkovsky J. Biosimilars in the therapy of inflammatory bowel diseases. Eur J Gastroenterol Hepatol. 2014;26(6):581-7.

298. Lukas M. Remsima ${ }^{\mathrm{TM}}$ : the first biosimilar infliximab. Gastroent Hepatol. 2014;68:178-9.

299. Papamichael K, Van Stappen T, Jairath V, Gecse K, Khanna R, D'Haens $G$, et al. Review article: pharmacological aspects of anti-TNF biosimilars in inflammatory bowel diseases. Aliment Pharmacol Ther. 2015;42(10):1158-69.

300. Richardson B. Biosimilars in perspective: regulation. Rheumatol. 2014;53:i5-6.

301. Rinaudo-Gaujous M, Paul S, Tedesco ED, Genin C, Roblin X, Peyrin-Biroulet L. Review article: biosimilars are the next generation of drugs for liver and gastrointestinal diseases. Aliment Pharmacol Ther. 2013;38(8):914-24.

302. Schreiber S, Luger T, Mittendorf T, Mrowietz U, Muller-Ladner $\mathrm{U}$, Schroder J, et al. Evolution of biologicals in inflammation medicine-biosimilars in gastroenterology, rheumatology and dermatology. Dtsch Med Wochenschr. 2014;139(47):2399-404.

303. Teixeira FV, Kotze PG, Damiao AO, Miszputen SJ. Biosimilars in inflammatory bowel diseases: an important moment for Brazilian gastroenterologists. Arq Gastroenterol. 2015;52(1):76-80.

304. Urbánek K. First biosimilar monoclonal antibody introduced to clinical praxis: Infliximab. Klin Farmakol Farm. 2014;28:19-22.

305. Wiland P. Biosymilars in the treatment of rheumatic diseases. Reumatologia. 2013;51:399-408.

306. Yoo DH. The rise of biosimilars: potential benefits and drawbacks in rheumatoid arthritis. Expert Rev Clin Immunol. 2014;10(8):981-3.

307. Declerck PJ. Biologicals and biosimilars: is similar the same? J Crohns Colitis. 2014;8(Suppl 1):S427.

308. Yamaguchi T. Current situations and the future prospect of monoclonal antibody products. Kokuritsu Iyakuhin Shokuhin Eisei Kenkyusho Hokoku. 2014;132:36-46.

309. Genazzani A, Altomare G, Balato N, Cusano F, De Pita O, Loconsole F, et al. Biosimilar infliximab: an expert view. G Ital Dermatol Venereol. 2015;150(4):449-59.

310. Baek K. Regulatory framework on biosimilar in Korea [abstract]. 10th Symposium on the Practical Applications of Mass Spectrometry in the Biotechnology Industry (Mass Spec 2013); 23-26 2013; Boston, MA: 34.

311. Esplugues Mota JV. Biosimilars: Potential clinical differences and European regulatory aspects. Ann Rheum Dis. 2014;73:7-8.

312. Kim YS, Choi BW, Yang SW, Shin SM, Nam SW, Roh YS, et al. Biosimilars: challenges and path forward. Biotechnol Bioprocess Eng. 2014;19(5):755-65.
313. Lee H. Is extrapolation of the safety and efficacy data in one indication to another appropriate for biosimilars? AAPS J. 2014;16(1):22-6.

314. Puig L, Carretero G, Dauden E, Ferrandiz C, Marron SE, Martorell A, et al. Biosimilars in dermatology: current situation (Part I). Actas Dermosifiliogr. 2015;106(7):545-9.

315. Puig L, Carretero G, Dauden E, Ferrandiz C, Marron SE, Martorell A, et al. Biosimilars in dermatology: current situation (Part II). Actas Dermosifiliogr. 2015;106(7):550-4.

316. Richardson P. EU regulatory update [abstract]. 9 December 2013. Available from: https://c.ymcdn.com/sites/www.casss. org/resource/resmgr/imported/CMCJapan2013_FINALProgram_ forWebsite.pdf. Accessed 2016 Jun 24.

317. Schellekens H, Lietzan E, Faccin F, Venema J. Biosimilar monoclonal antibodies: the scientific basis for extrapolation. Expert Opin Biol Ther. 2015;15(11):1633-46.

318. Scott BJ, Klein AV, Wang J. Biosimilar monoclonal antibodies: A Canadian regulatory perspective on the assessment of clinically relevant differences and indication extrapolation. J Clin Pharmacol. 2015;55(Suppl 3):S123-32.

319. Siu EC, Wyatt G. Canadian public reimbursement of subsequent entry biologics (SEBS)/biosimilars. Value Health. 2015;18(3):A168-9.

320. Young KE, Rémuzat C, Urbinati D, Toumi M. Boosting biosimilars uptake in European countries. Value Health. 2014;17:A408-9.

321. Reinisch W, Smolen J. Biosimilar safety factors in clinical practice. Semin Arthritis Rheum. 2015;44(6 Suppl):S9-15.

322. Zrubka Z, Vezer B, Sebeszta M. Authorised manufacturing changes of therapeutic monoclonal antibodies in EPAR documents. Ann Rheum Dis. 2015;74:A94.

323. Fonseca JE, Goncalves J, Araujo F, Cordeiro I, Teixeira F, Canhao H, et al. The Portuguese Society of Rheumatology position paper on the use of biosimilars. Acta Reumatol Port. 2014;39(1):60-71.

324. Pavelka K. EULAR recommendations for the management of rheumatoid arthritis - differences between versions from 2013 and 2010. Čes Revmatol. 2014;22:70-80.

325. Amiot A, Peyrin-Biroulet L. Current, new and future biological agents on the horizon for the treatment of inflammatory bowel diseases. Therap Adv Gastroenterol. 2015;8(2):66-82.

326. Feldman SR. Inflammatory diseases: Integrating biosimilars into clinical practice. Semin Arthritis Rheum. 2015;44(6 Suppl):S16-21.

327. Fonseca JE. The therapeutic landscape in RA-BDMARDS biosimilars and beyond. Ann Rheum Dis. 2015;74:2.

328. Puig L. Biosimilars in dermatology: starting with infliximab. Actas Dermosifiliogr. 2013;104(3):175-80.

329. Braun J. Latest update on biosimilars-chances and risks. Ann Rheum Dis. 2014;73:32.

330. Woron J, Kocic I. The story of biosimilars-chance or threat? Pol Merkur Lekarski. 2014;37(221):311-5.

331. Strojil J. Biosimilars-specific features of the approval process in the European Union. Klin Farmakol Farm. 2014;28:14-8.

332. Choy E, Jacobs IA. Biosimilar safety considerations in clinical practice. Semin Oncol. 2014;41(Suppl 1):S3-14.

333. Geiler J, Buch M, McDermott MF. Anti-TNF treatment in rheumatoid arthritis. Curr Pharm Des. 2011;17(29):3141-54.

334. Ma Y, Wang T, Ma Y, Lin B. Research progress of the clinical pharmacokinetics of etanercept and its biosimilars. Chinese $\mathrm{J}$ New Drugs. 2013;24:2896-902.

335. Pecen PE, Kaiser PK. Current phase 1/2 research for neovascular age-related macular degeneration. Curr Opin Ophthalmol. 2015;26(3):188-93. 